Supporting Information for:

\title{
Examining the Modular Synthesis of [Cp*Rh] Monohydrides Supported by Chelating Diphosphine Ligands
}

\author{
Chelsea G. Comadoll, ${ }^{a}$ Wade C. Henke, ${ }^{a}$ Julie A. Hopkins Leseberg, ${ }^{a}$ Justin T. Douglas, ${ }^{b}$ Allen G. Oliver, ${ }^{c}$ \\ Victor W. Day, ${ }^{a}$ and James D. Blakemore ${ }^{*, a}$ \\ ${ }^{\text {a }}$ Department of Chemistry, University of Kansas, \\ 1567 Irving Hill Road, Lawrence, Kansas 66045 United States \\ ${ }^{\mathrm{b}}$ Nuclear Magnetic Resonance Laboratory, Molecular Structures Group, University of Kansas, \\ 2034 Becker Drive, Lawrence, Kansas 66047, United States \\ ${ }^{\mathrm{c}}$ Department of Chemistry and Biochemistry, University of Notre Dame, \\ 149 Stepan Chemistry Hall, Notre Dame, Indiana 46556 United States \\ * To whom correspondence should be addressed. \\ E-mail: blakemore@ku.edu; phone: +1 (785) 864-3019
}

\section{Contents}

Chart S1: Complexes of Interest

\section{NMR Spectra}

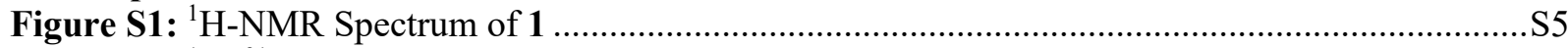

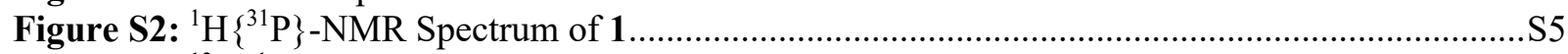

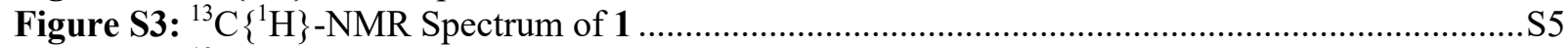

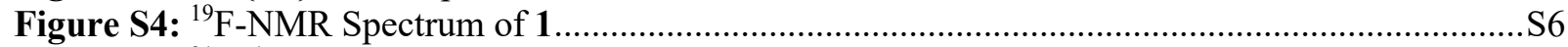

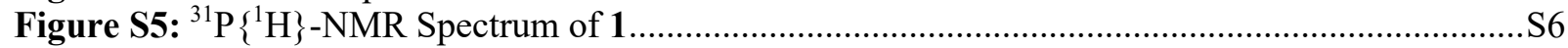

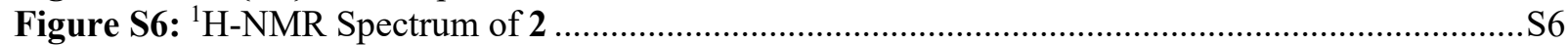

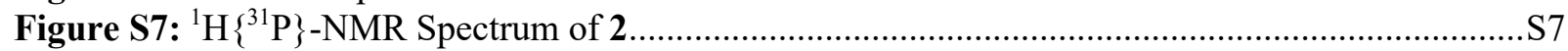

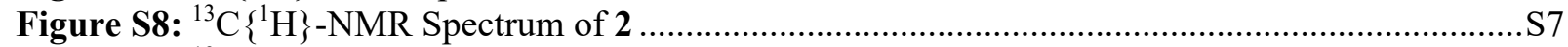

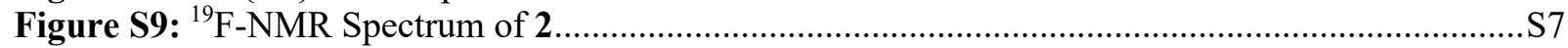

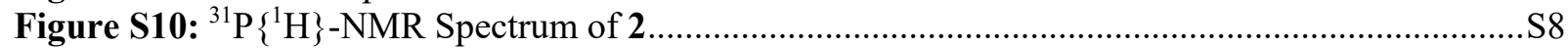

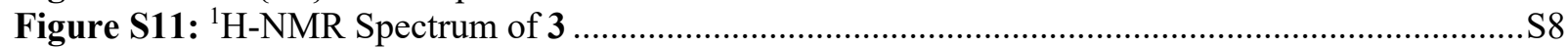

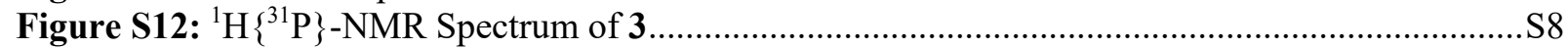

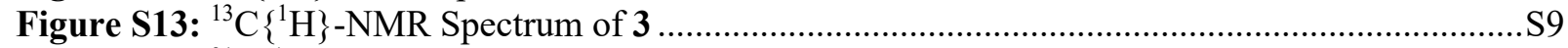

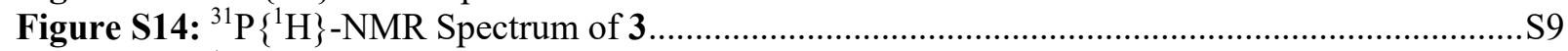

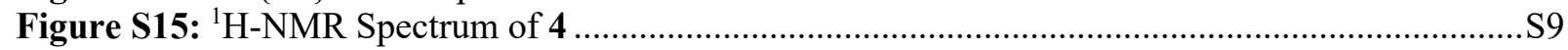

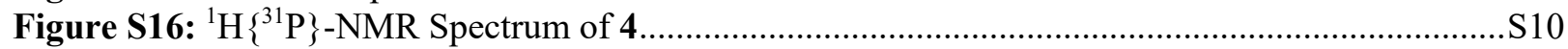

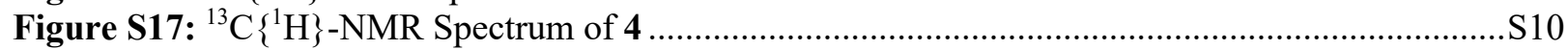

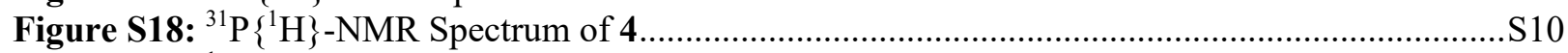

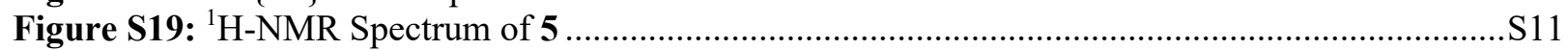

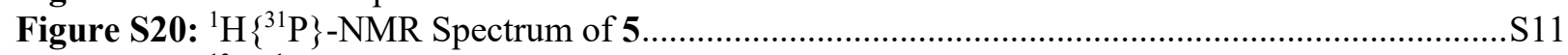

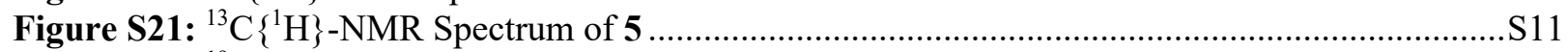

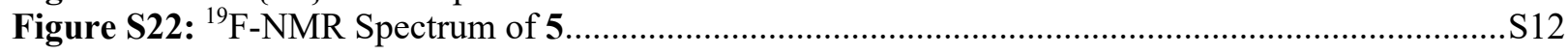




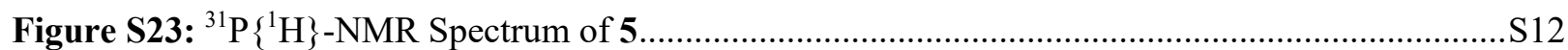

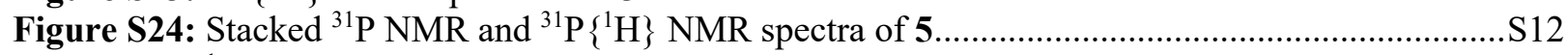

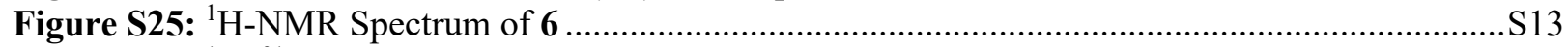

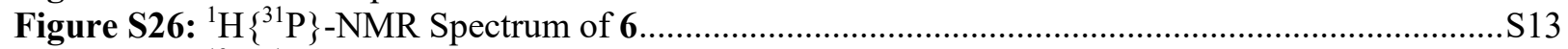

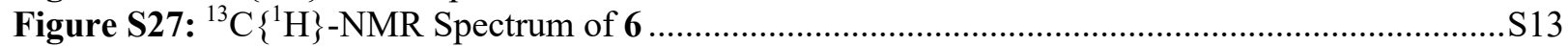

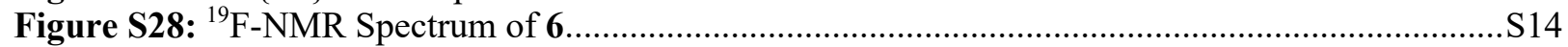

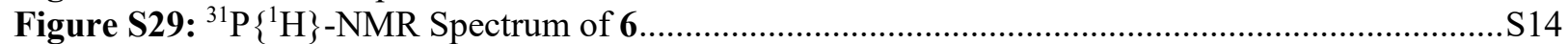

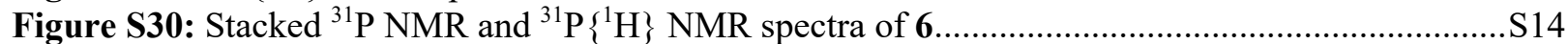

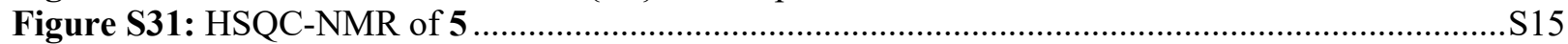

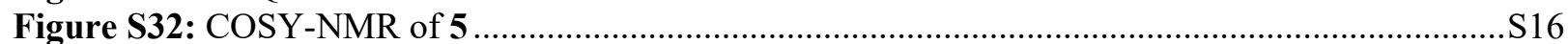

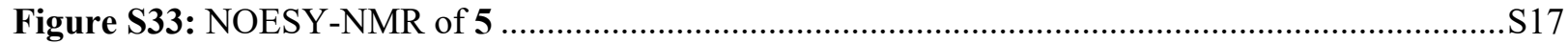

\section{Infrared Spectra}

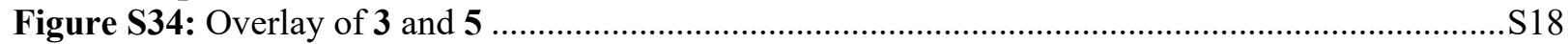

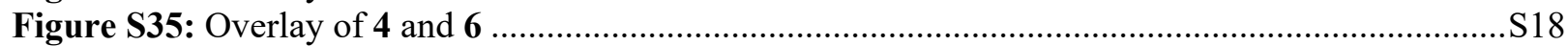

\section{Hydrogen Evolution Study of 5 and 6}

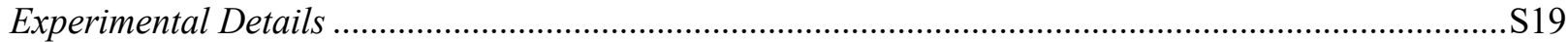

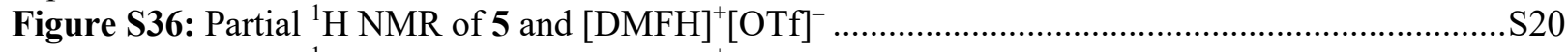

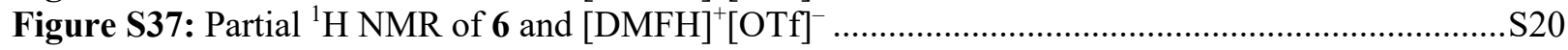

\section{Multifrequency ${ }^{1} \mathrm{H}$ NMR}

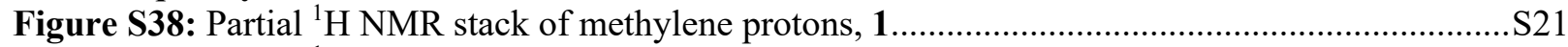

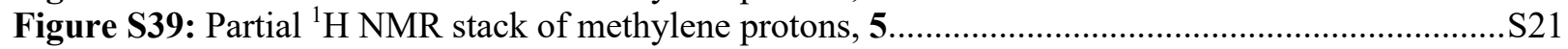

\section{${ }^{1}$ H NMR Digital Simulations}

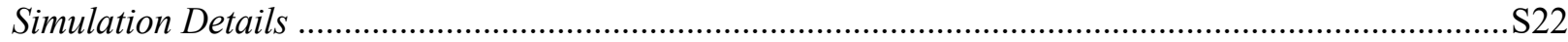

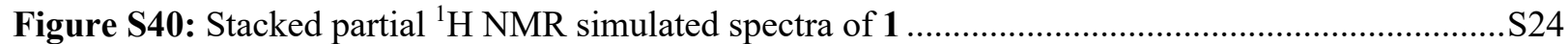

Figure S41: Sequential simulated spectra probing hydride response in 5 ........................................S25

\section{Crystallographic Information}

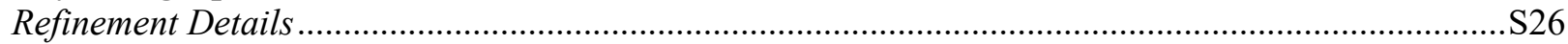

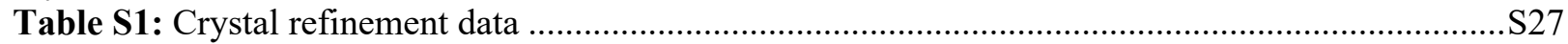

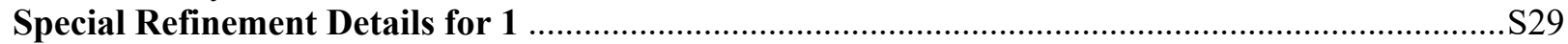

Figure S42: Solid-state structure (counteranion, phenyls omitted) of the molecular cation of 1 ...........S30

Figure S43: Solid-state structure (counteranion omitted) of the molecular cation of 1 .....................S30

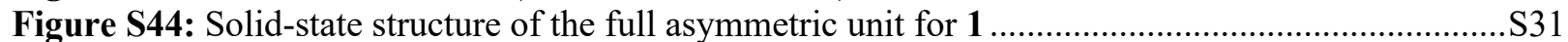

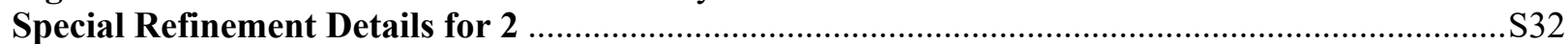

Figure S45: Solid-state structure (counteranion, phenyls omitted) of the first molecular cation of 2 ...S33

Figure S46: Ball-and-stick representation (counteranion, phenyls omitted) of the first molecular

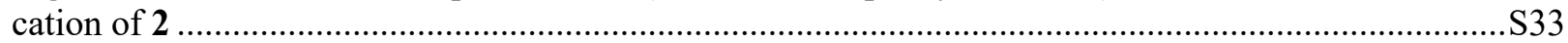

Figure S47: Solid-state structure (counteranion omitted) of the first molecular cation of 2 .................S34

Figure S48: Ball-and-stick representation (counteranion omitted) of the first molecular cation of 2 ....S34

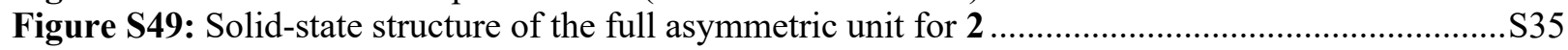

Figure S50: Ball-and-stick representation of the full asymmetric unit for the structure of 2...............S35

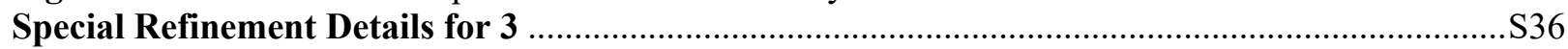

Figure S51: Solid-state structure (phenyls omitted) of the molecular core for the asymmetric unit

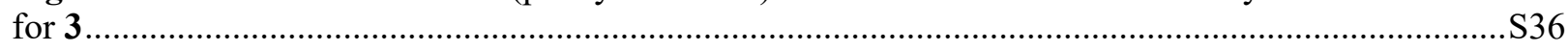

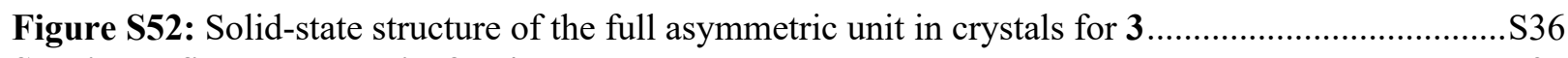

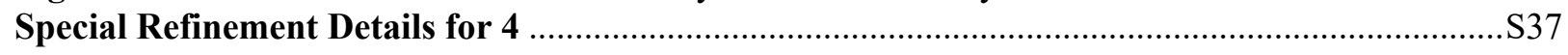




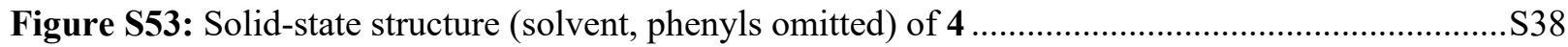

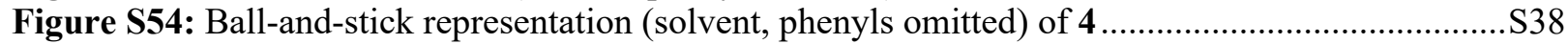

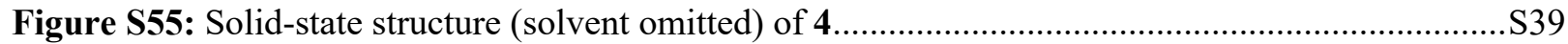

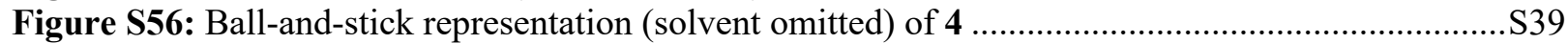

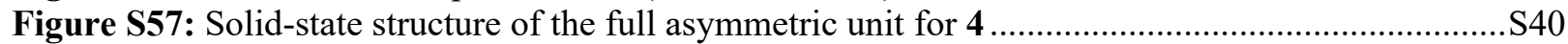

Figure S58: Ball-and-stick representation of the solid-state structure for the full asymmetric unit

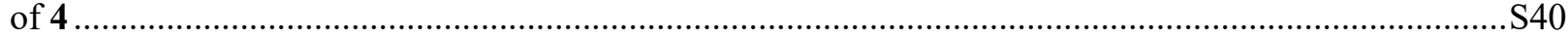

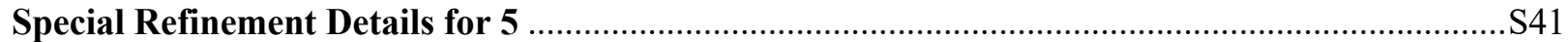

Figure S59: Solid-state structure (counteranion, phenyls omitted) of the molecular cation in $\mathbf{5}$.........S42

Figure S60: Solid-state structure (counteranion omitted) of the molecular cation in $\mathbf{5}$.....................S43

Figure S61: Solid-state structure for a complete anion/cation pair (two asymmetric units) in $\mathbf{5}$..........S44

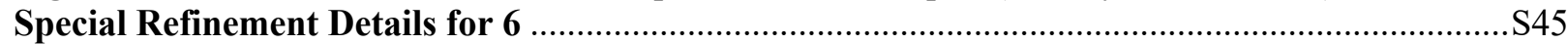

Figure S62: Solid-state structure (counteranion, phenyls omitted) of 6........................................S46

Figure S63: Ball-and-stick representation (counteranion, phenyls omitted) of 6..............................S46

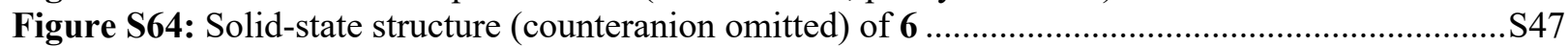

Figure S65: Ball-and-stick representation (counteranion omitted) of 6 ............................................S47

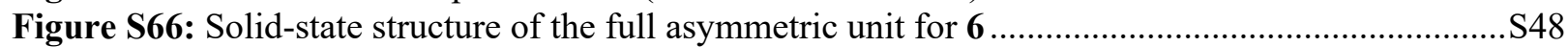

Figure S67: Ball-and-stick representation of the full asymmetric unit for 6.....................................S48

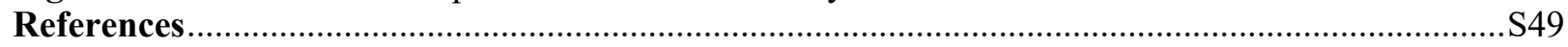




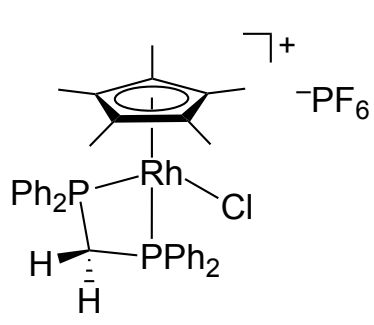

1

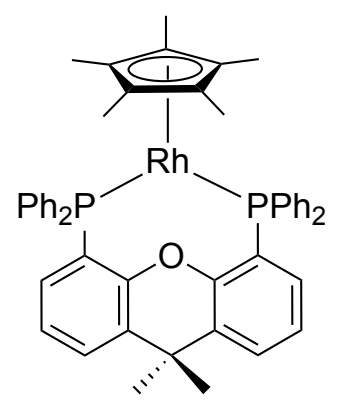

4

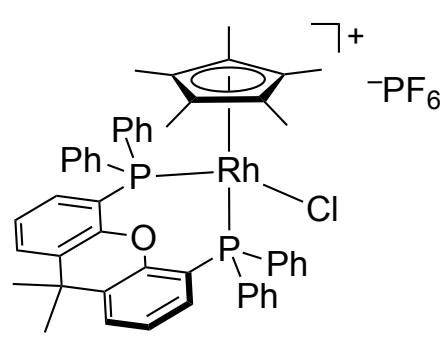

2

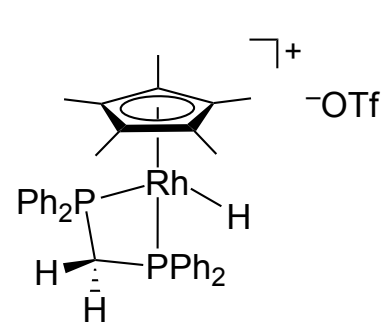

5

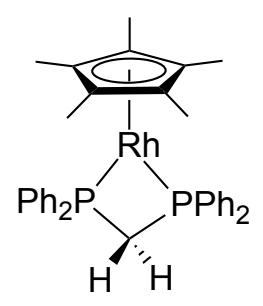

3

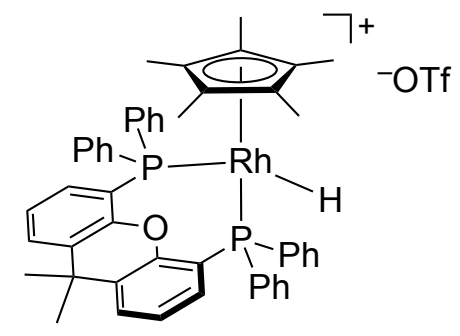

6

Chart S1: Complexes described in the supporting information. 

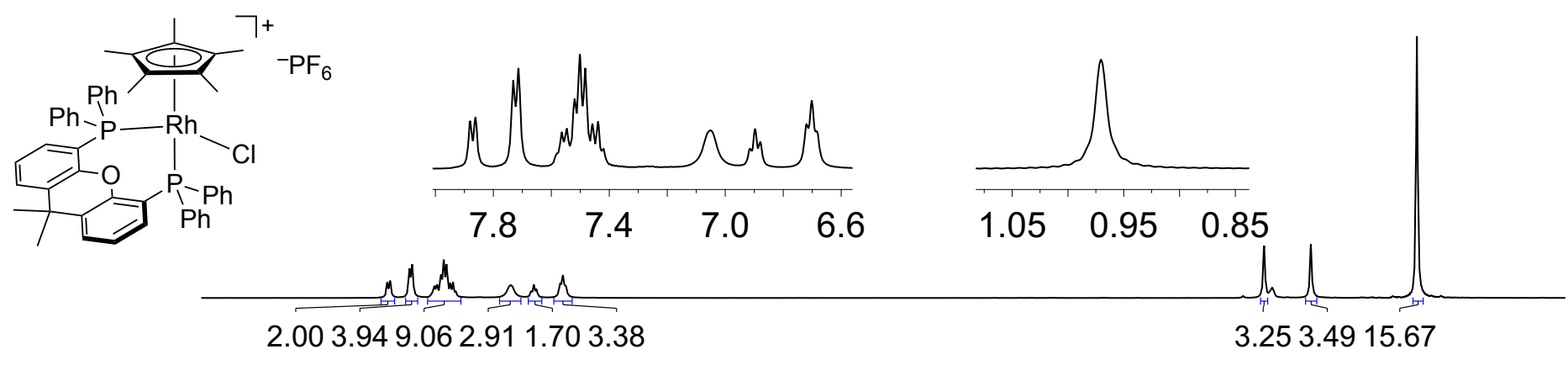

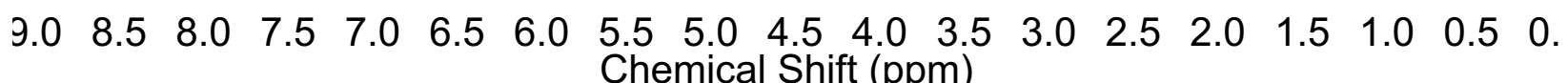

Figure S7: ${ }^{1} \mathrm{H}\left\{{ }^{31} \mathrm{P}\right\}$ NMR spectrum $\left(400 \mathrm{MHz}, \mathrm{CD}_{3} \mathrm{CN}\right)$ of 2 . Because deuterated solvent signal is diminished in this spectrum, the signal for $\mathrm{Cp}^{*}$ methyl protons was used as internal reference and set to value of 0.9703 ppm based on nondecoupled data shown in Figure S6.

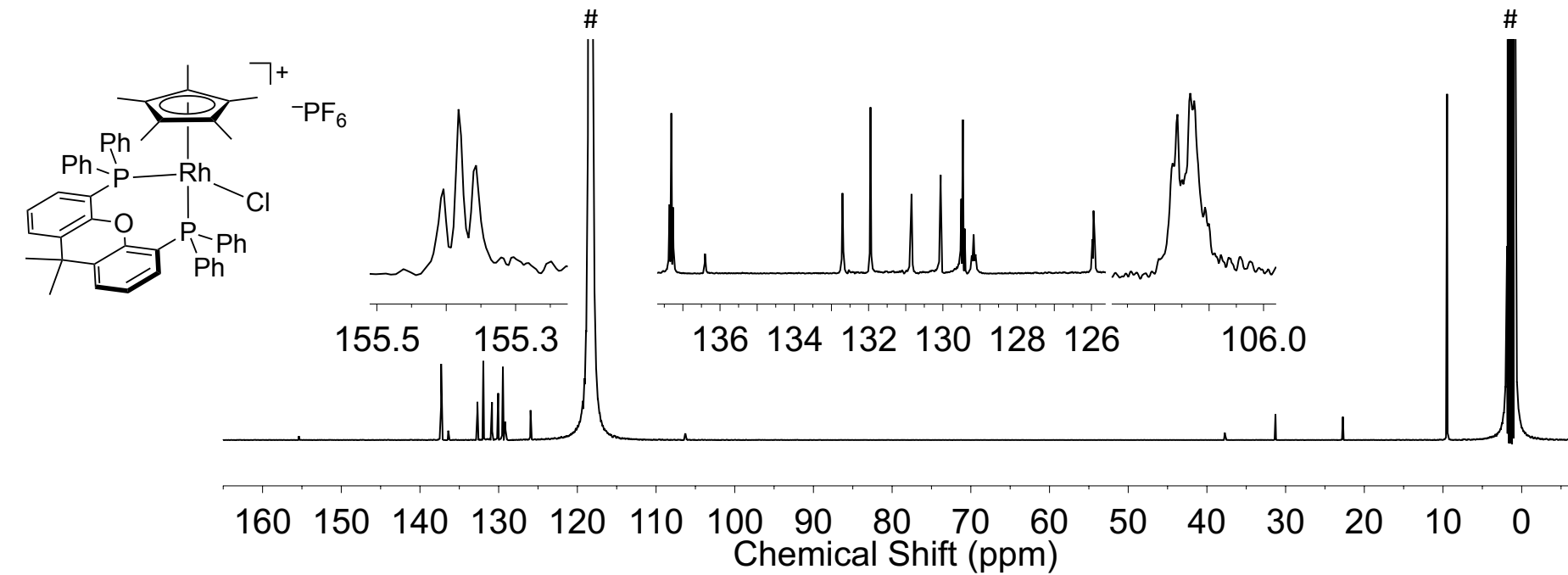

Figure S8: ${ }^{13} \mathrm{C}\left\{{ }^{1} \mathrm{H}\right\}$ NMR spectrum $\left(126 \mathrm{MHz}, \mathrm{CD}_{3} \mathrm{CN}\right)$ of $\mathbf{2}$. The signals indicated by \# are associated with acetonitrile.
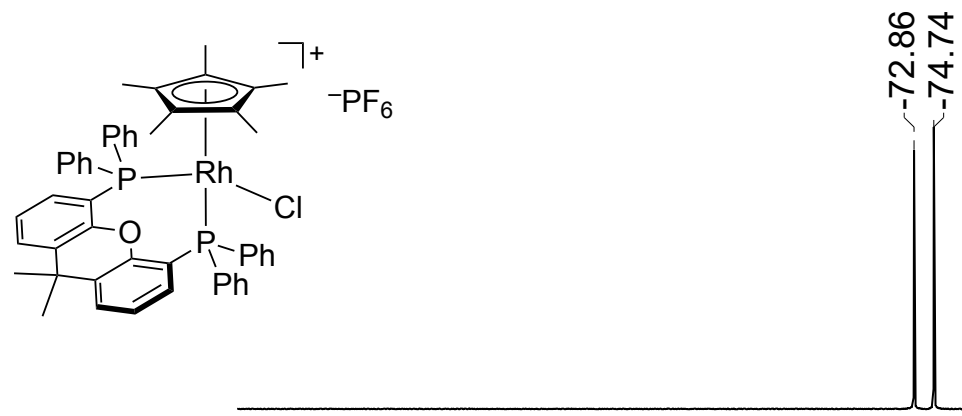

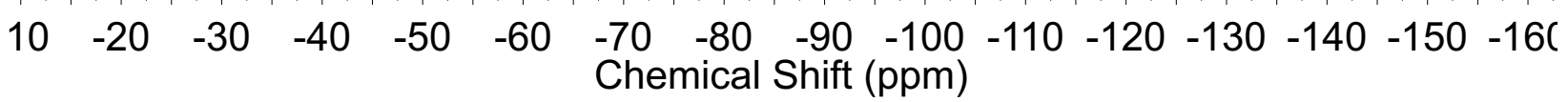

Figure S9: ${ }^{19} \mathrm{~F}$ NMR spectrum $\left(376 \mathrm{MHz}, \mathrm{CD}_{3} \mathrm{CN}\right)$ of 2. 


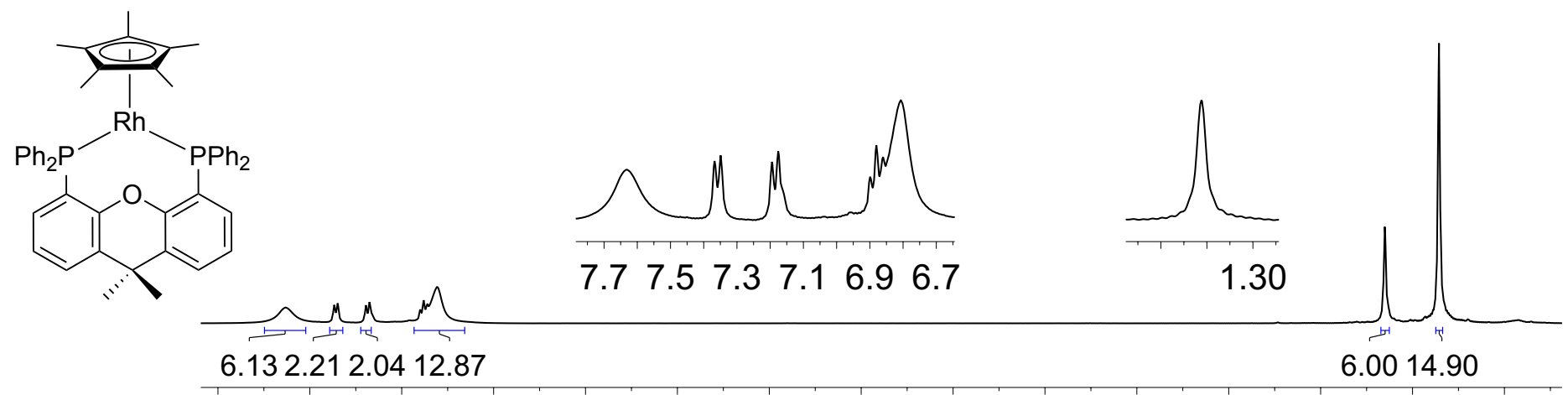

\section{$\begin{array}{lllllllllllllll}3.0 & 7.5 & 7.0 & 6.5 & 6.0 & 5.5 & 5.0 & 4.5 & 4.0 & 3.5 & 3.0 & 2.5 & 2.0 & 1.5 & 1.0\end{array}$ Chemical Shift (ppm)}

Figure S16: ${ }^{1} \mathrm{H}\left\{{ }^{31} \mathrm{P}\right\}$ NMR spectrum $\left(400 \mathrm{MHz}, \mathrm{C}_{6} \mathrm{D}_{6}\right)$ of 4. Because deuterated solvent signal is diminished in this spectrum, the signal for $\mathrm{Cp}^{*}$ methyl protons was used as internal reference and set to value of $1.3559 \mathrm{ppm}$ based on nondecoupled data shown in Figure S15.

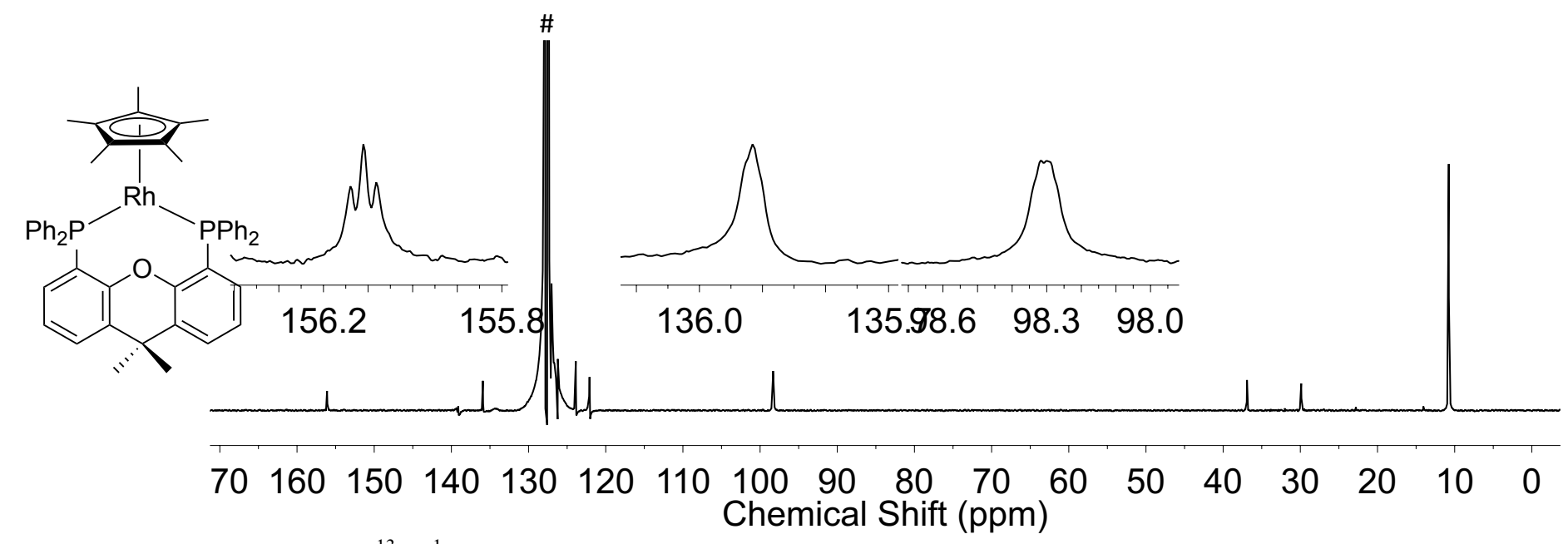

Figure S17: ${ }^{13} \mathrm{C}\left\{{ }^{1} \mathrm{H}\right\}$ NMR spectrum $\left(126 \mathrm{MHz}, \mathrm{C}_{6} \mathrm{D}_{6}\right)$ of $\mathbf{4}$. The signal indicated by \# is associated with benzene.

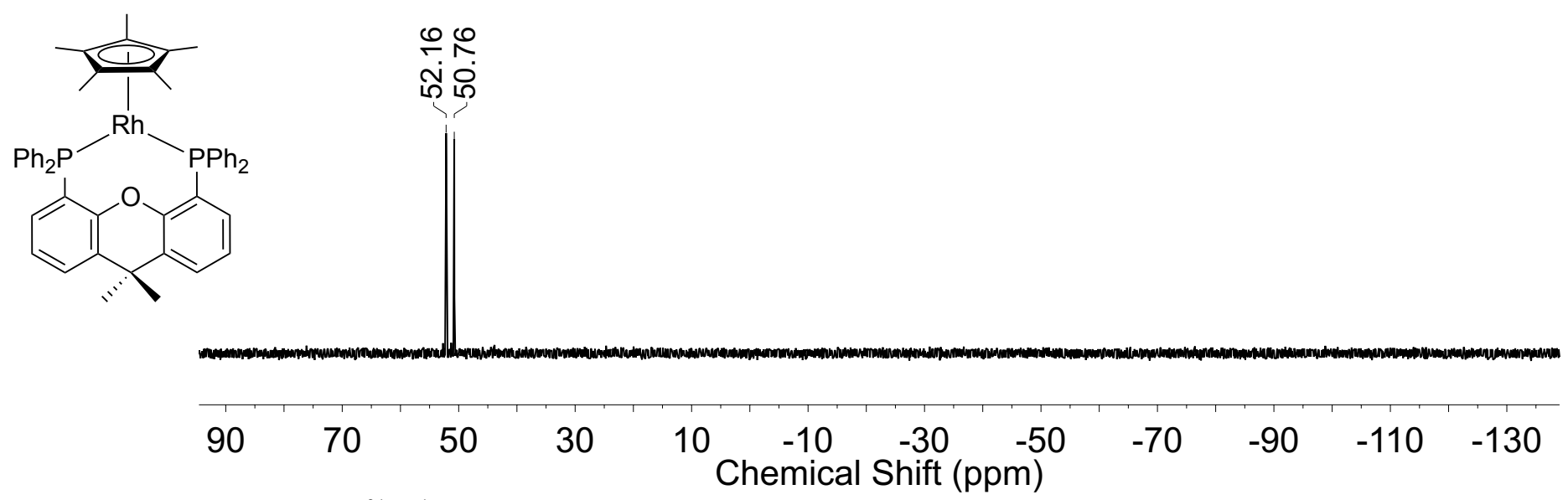

Figure S18: ${ }^{31} \mathrm{P}\left\{{ }^{1} \mathrm{H}\right\}$ NMR spectrum $\left(162 \mathrm{MHz}, \mathrm{C}_{6} \mathrm{D}_{6}\right)$ of 4 . 


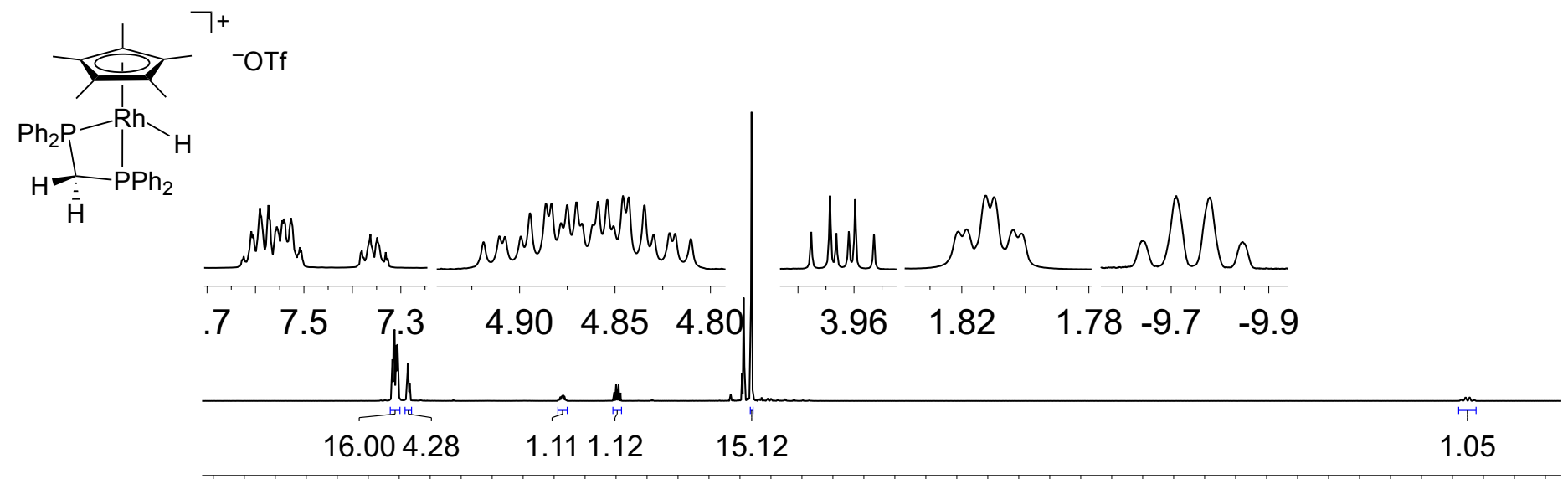

$\begin{array}{llllllllllllllllllllll}10 & 9 & 8 & 7 & 6 & 5 & 4 & 3 & 2 & 1 & 0 & -1 & -2 & -3 & -4 & -5 & -6 & -7 & -8 & -9 & -10 & -11\end{array}$ Chemical Shift (ppm)

Figure S19: ${ }^{1} \mathrm{H}$ NMR spectrum $\left(400 \mathrm{MHz}, \mathrm{CD}_{3} \mathrm{CN}\right)$ of 5.
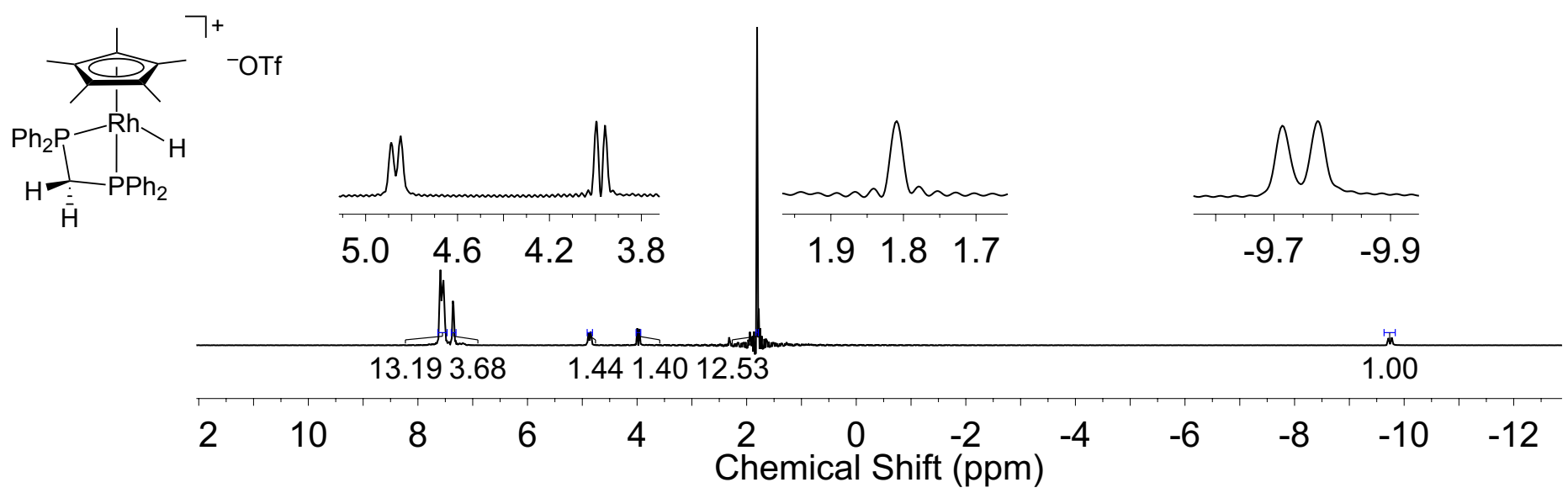

Figure S20: ${ }^{1} \mathrm{H}\left\{{ }^{31} \mathrm{P}\right\}$ NMR spectrum $\left(400 \mathrm{MHz}, \mathrm{CD}_{3} \mathrm{CN}\right)$ of $\mathbf{5}$. Because deuterated solvent signal is diminished in this spectrum, the signal for $\mathrm{Cp}^{*}$ methyl protons was used as internal reference and set to value of 1.8096 ppm based on nondecoupled data shown in Figure S19.

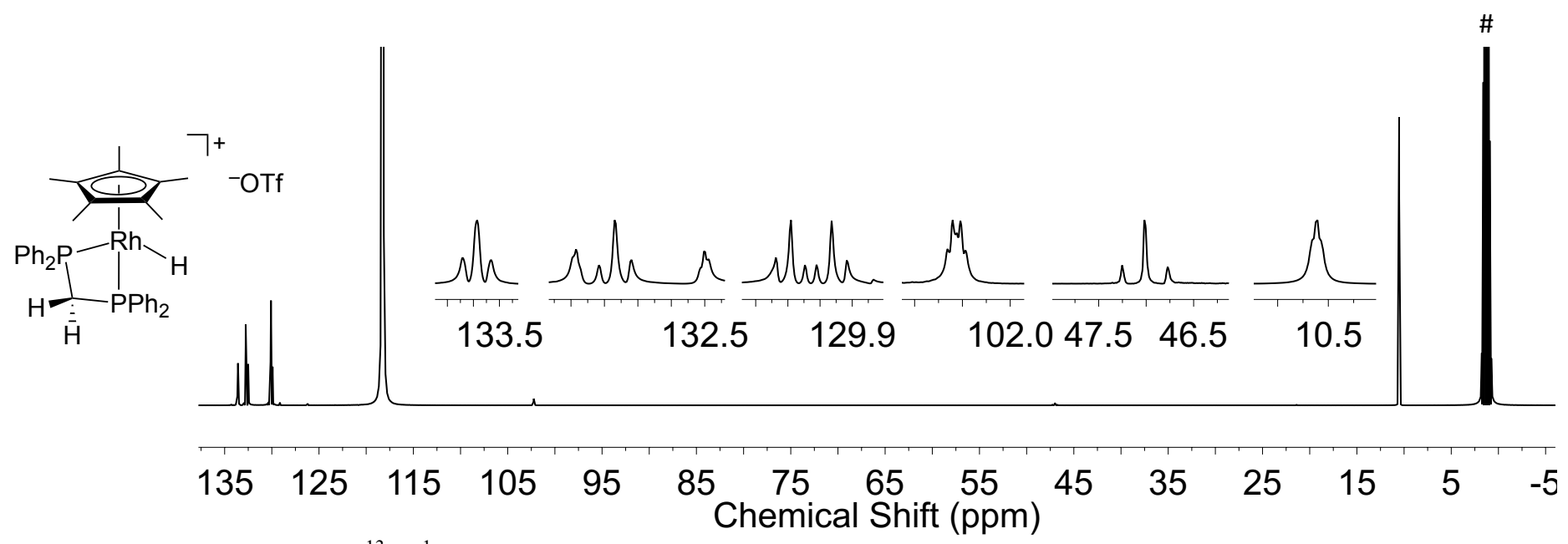

Figure S21: ${ }^{13} \mathrm{C}\left\{{ }^{1} \mathrm{H}\right\}$ NMR spectrum $\left(126 \mathrm{MHz}, \mathrm{CD}_{3} \mathrm{CN}\right)$ of $\mathbf{5}$. The signals indicated by \# are associated with acetonitrile. 


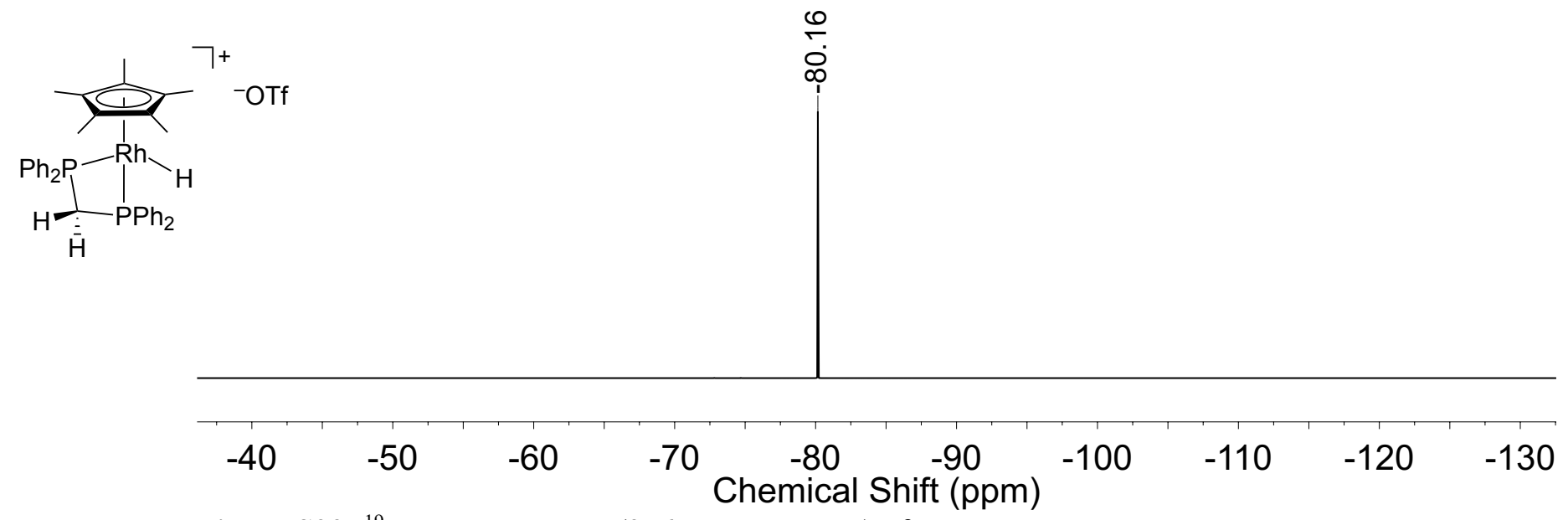

Figure S22: ${ }^{19} \mathrm{~F}$ NMR spectrum $\left(376 \mathrm{MHz}, \mathrm{CD}_{3} \mathrm{CN}\right)$ of $\mathbf{5}$.
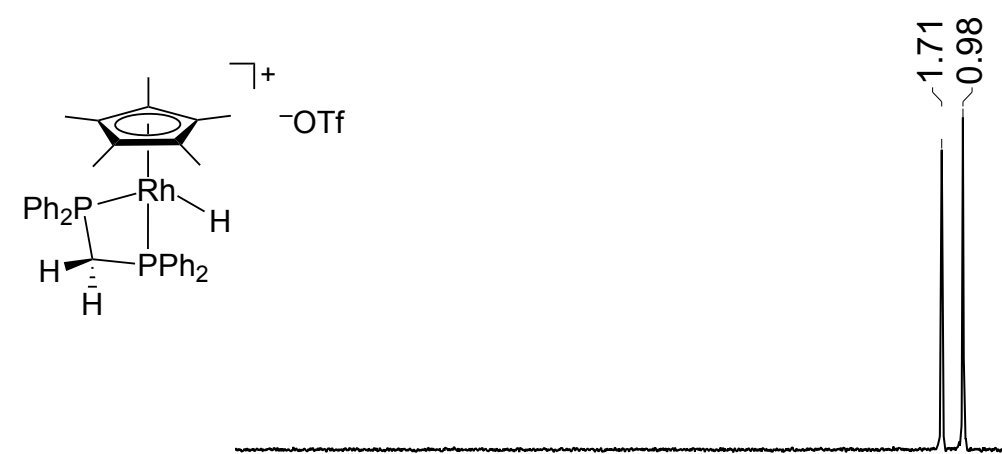

$\begin{array}{lllllllllllll}6 & 22 & 18 & 14 & 10 & 6 & \begin{array}{c}2 \\ \text { Chemical Shift }(\mathrm{ppm})\end{array} & -10 & -14 & -18 & -22 & -26 & -3\end{array}$

Figure S23: ${ }^{31} \mathrm{P}\left\{{ }^{1} \mathrm{H}\right\}$ NMR spectrum $\left(162 \mathrm{MHz}, \mathrm{CD}_{3} \mathrm{CN}\right)$ of $\mathbf{5}$.

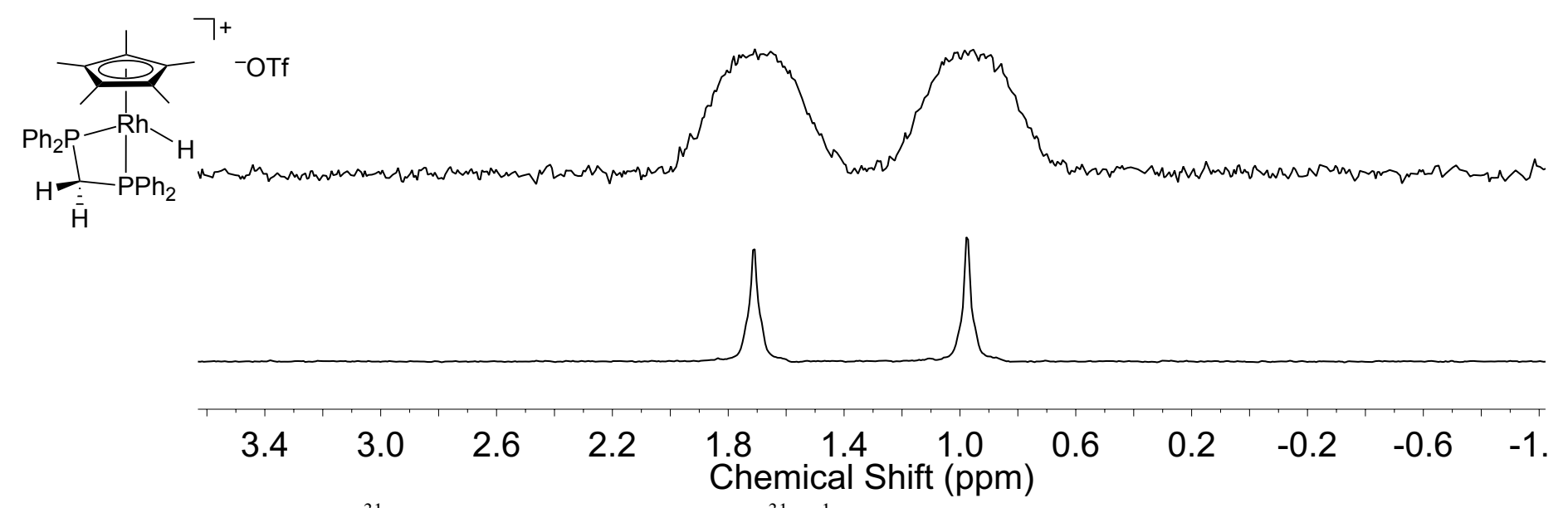

Figure S24: ${ }^{31} \mathrm{P}$ NMR spectrum (upper) and ${ }^{31} \mathrm{P}\left\{{ }^{1} \mathrm{H}\right\}$ NMR spectrum (lower) of $5\left(162 \mathrm{MHz}, \mathrm{CD}_{3} \mathrm{CN}\right)$. 


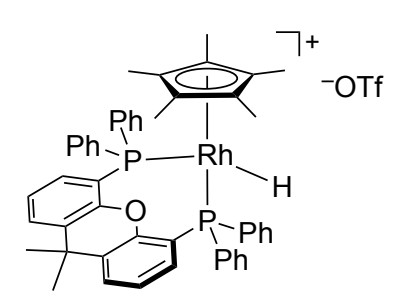

$\begin{array}{lllllllllllllllll}74.0 & -75.0 & -76.0 & -77.0 & -78.0 & -79.0 & -80.0 & -81.0 & -82.0 & -83.0 & -84.0 & -85.0 & -86.0 & -87.0\end{array}$ Chemical Shift (ppm)

Figure S28: ${ }^{19} \mathrm{~F}$ NMR spectrum $\left(376 \mathrm{MHz}, \mathrm{CD}_{3} \mathrm{CN}\right)$ of 6.
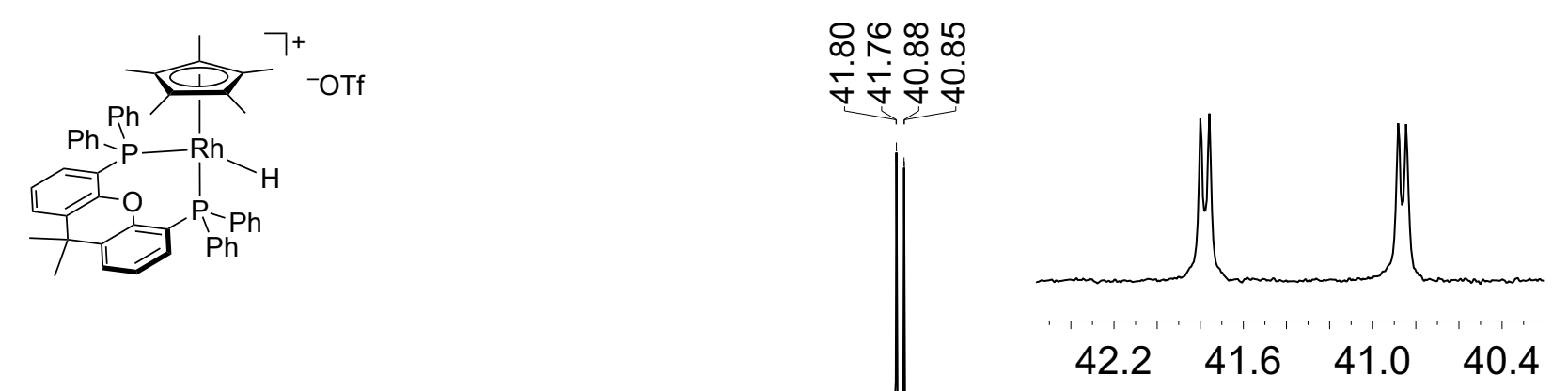

$\begin{array}{lllllllllllllllll}110 & 100 & 90 & 80 & 70 & 60 & 50 & 40 & 30 & 20 & 10 & 0 & -10 & -20 & -30 & -40 & -50\end{array}$ Chemical Shift (ppm)

Figure S29: ${ }^{31} \mathrm{P}\left\{{ }^{1} \mathrm{H}\right\}$ NMR spectrum $\left(162 \mathrm{MHz}, \mathrm{CD}_{3} \mathrm{CN}\right)$ of $\mathbf{6}$.

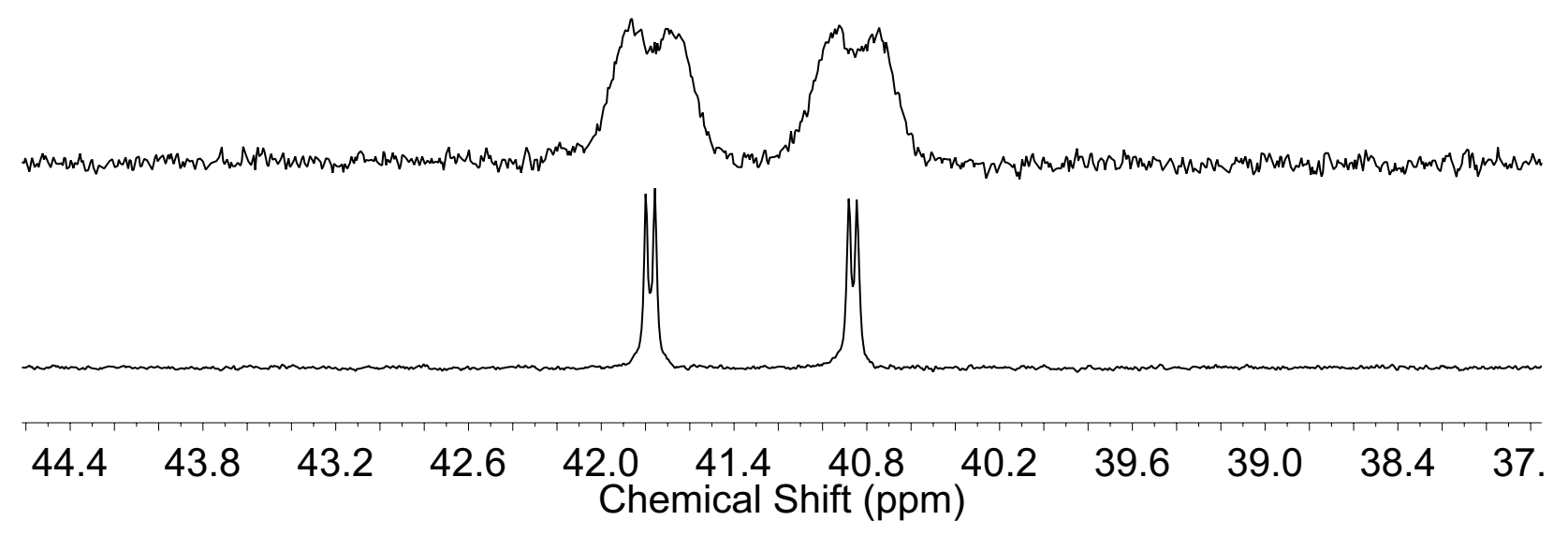

Figure S30: ${ }^{31} \mathrm{P}$ NMR spectrum (upper) and ${ }^{31} \mathrm{P}\left\{{ }^{1} \mathrm{H}\right\}$ NMR spectrum (lower) of $6\left(162 \mathrm{MHz}, \mathrm{CD}_{3} \mathrm{CN}\right)$. 


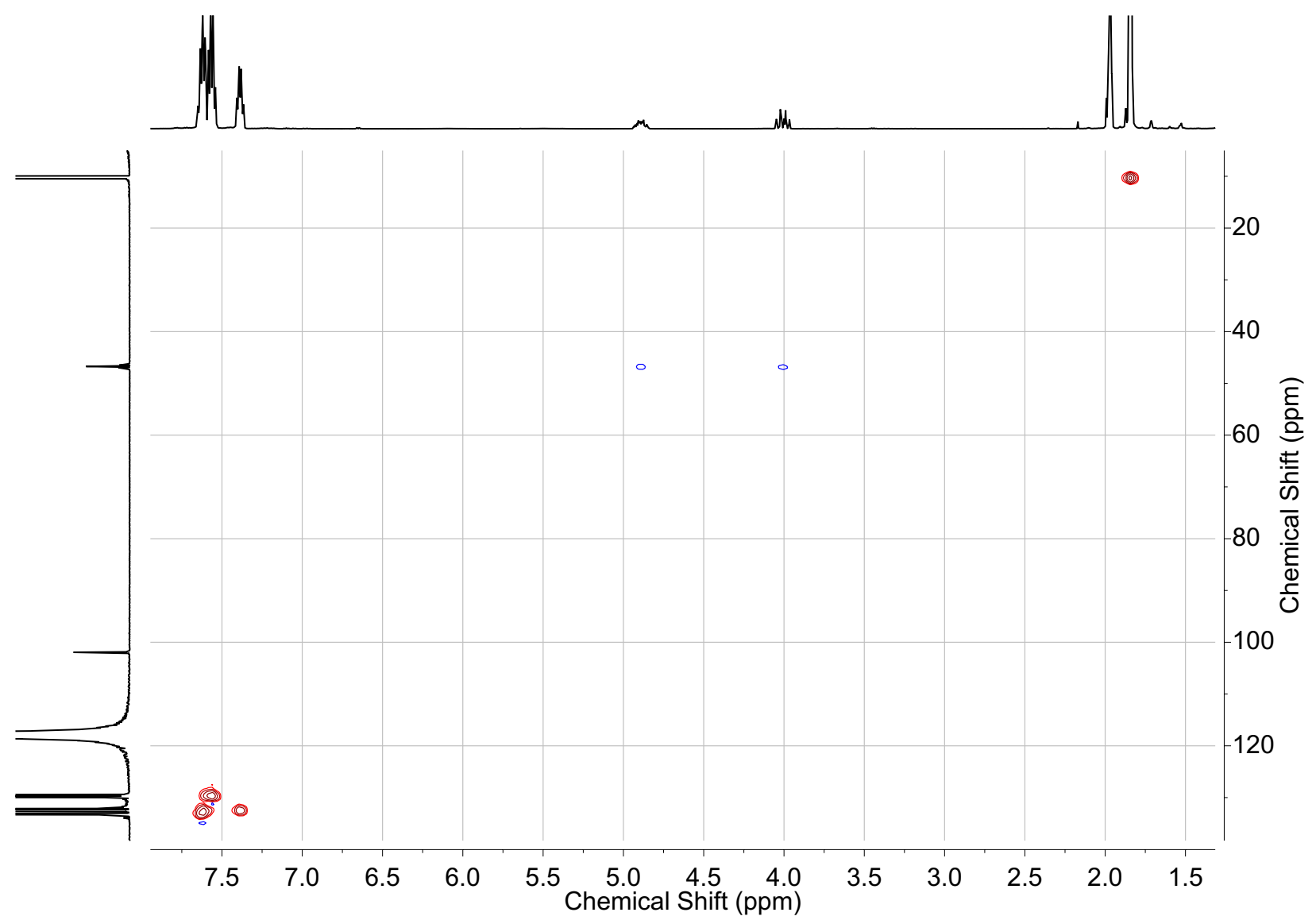

Figure S31: Full HSQC-NMR spectrum $\left(\mathrm{CD}_{3} \mathrm{CN}\right)$ of $\mathbf{5}$ (above) and inset of aromatic region (right).
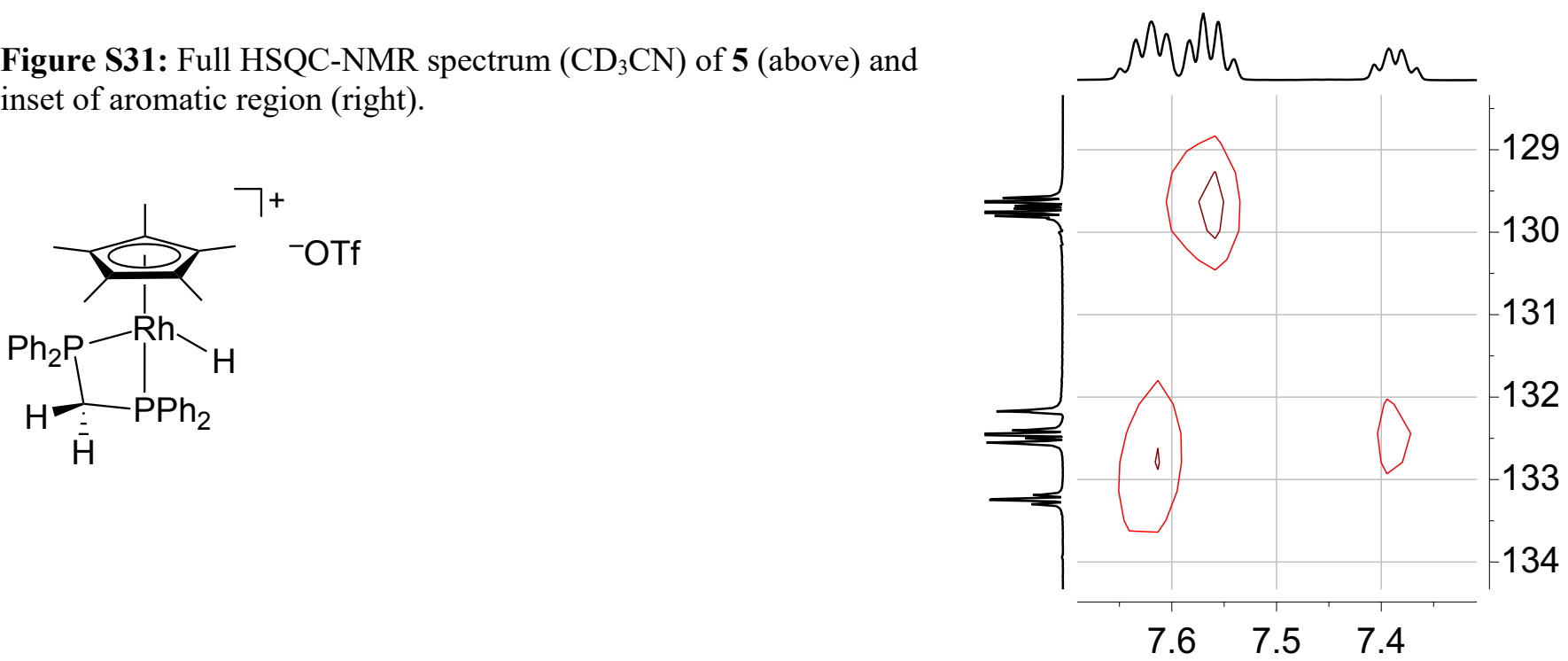


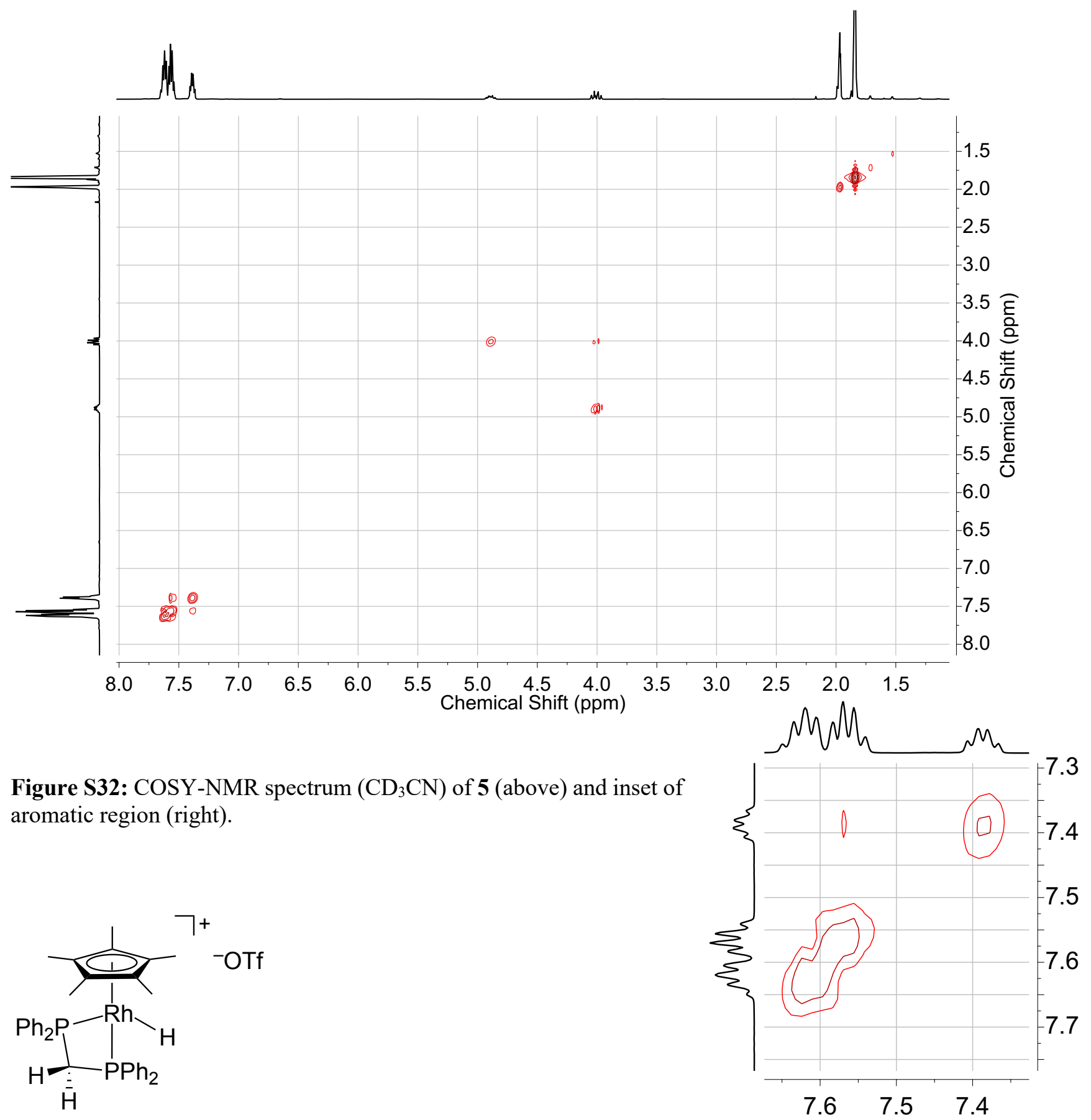



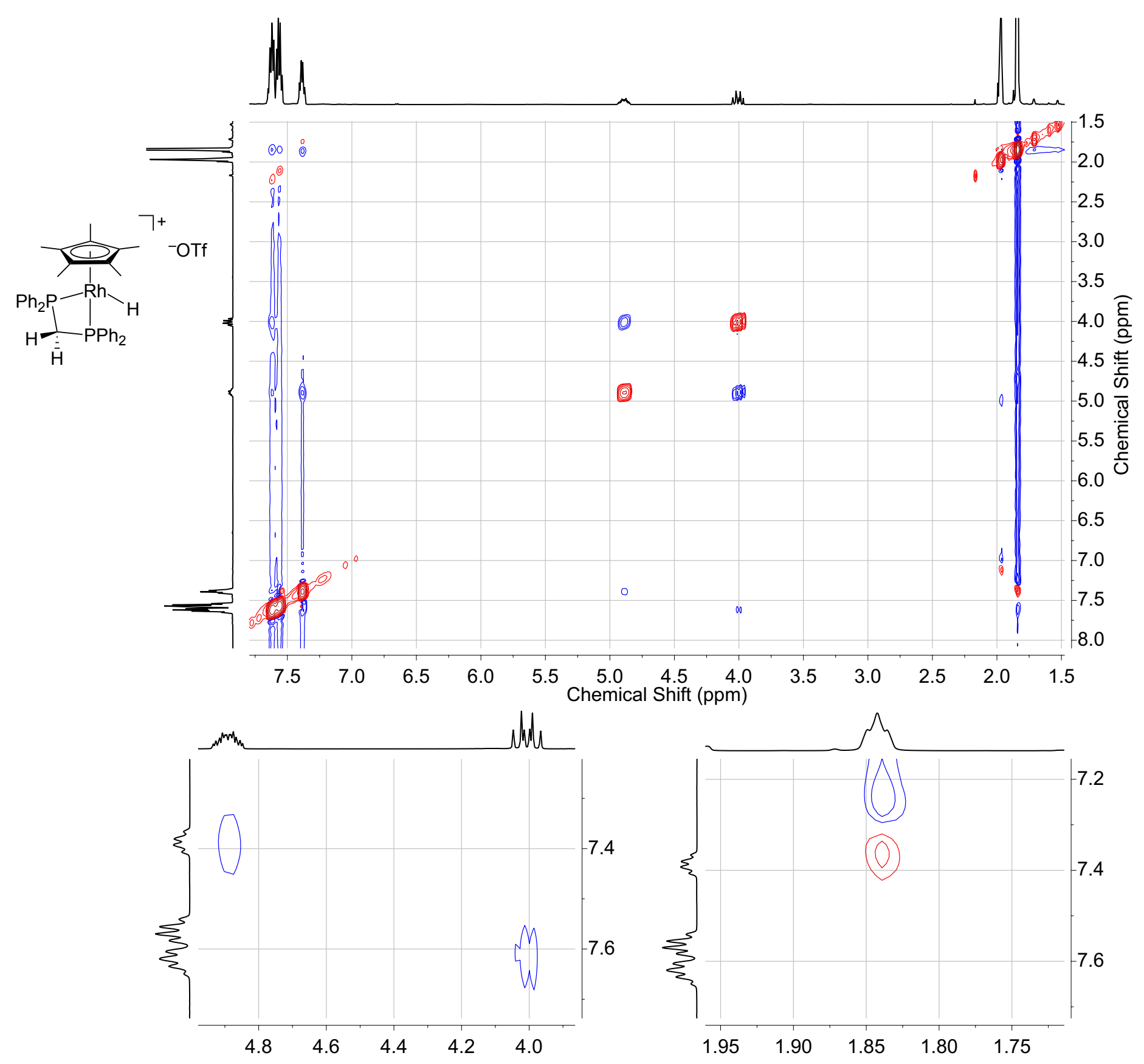

Figure S33: NOESY-NMR spectrum $\left(\mathrm{CD}_{3} \mathrm{CN}\right)$ of 5 (upper large panel) and inset of methylene protons, aromatic region and $\mathrm{Cp}^{*}$ methyl protons (lower two panels). 


\section{Infrared Spectroscopy}

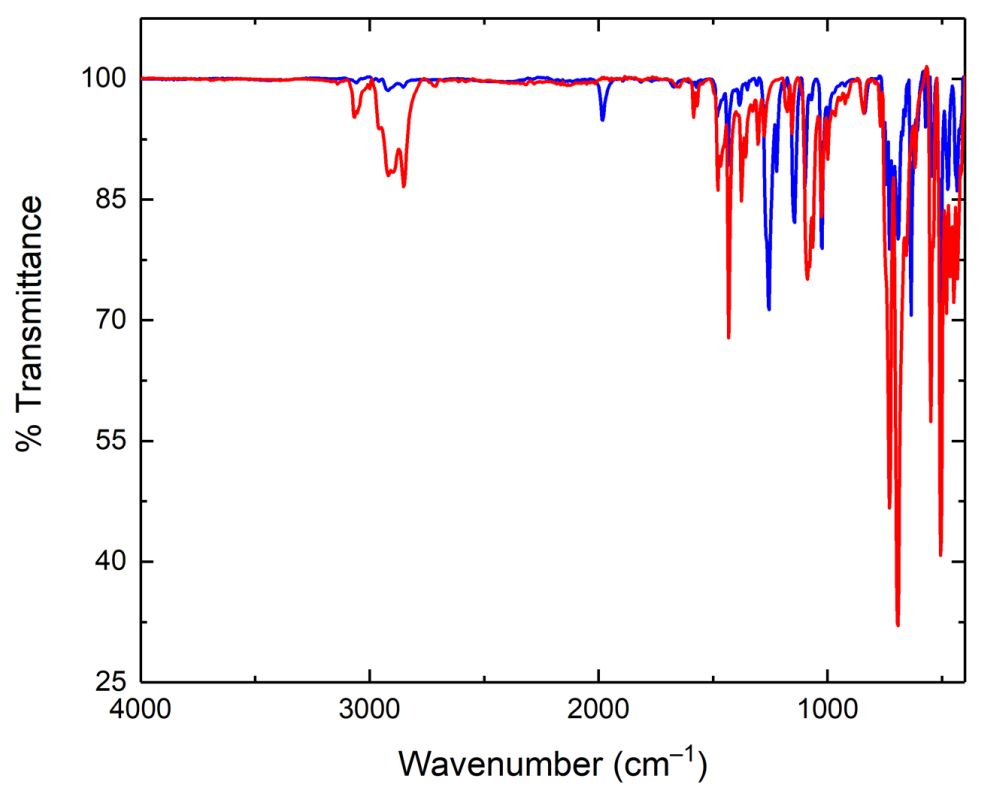

Figure S34: Infrared Spectrum of 3 (red) overlaid with 5 (blue). The peak present at $1982 \mathrm{~cm}^{-1}$ represents the $\mathrm{Rh}-\mathrm{H}$ frequency.

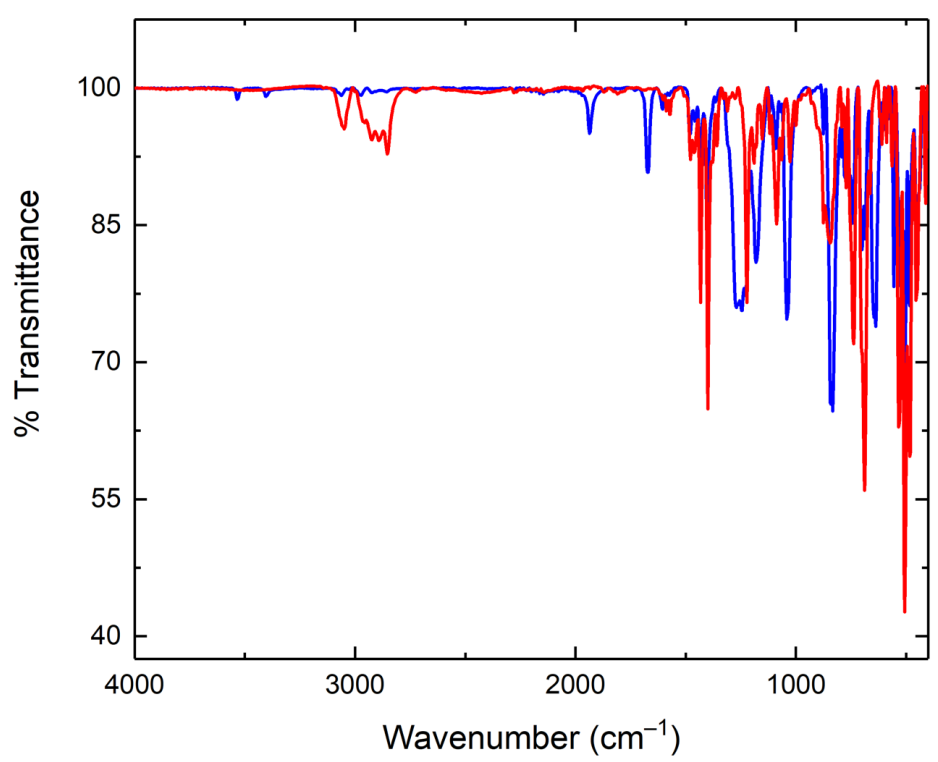

Figure S35: Infrared Spectrum of 4 (red) overlaid with 6 (blue). The peak present at $1936 \mathrm{~cm}^{-1}$ represents the $\mathrm{Rh}-\mathrm{H}$ frequency. 


\section{Hydrogen Evolution Study of 5 and 6}

Experimental Details
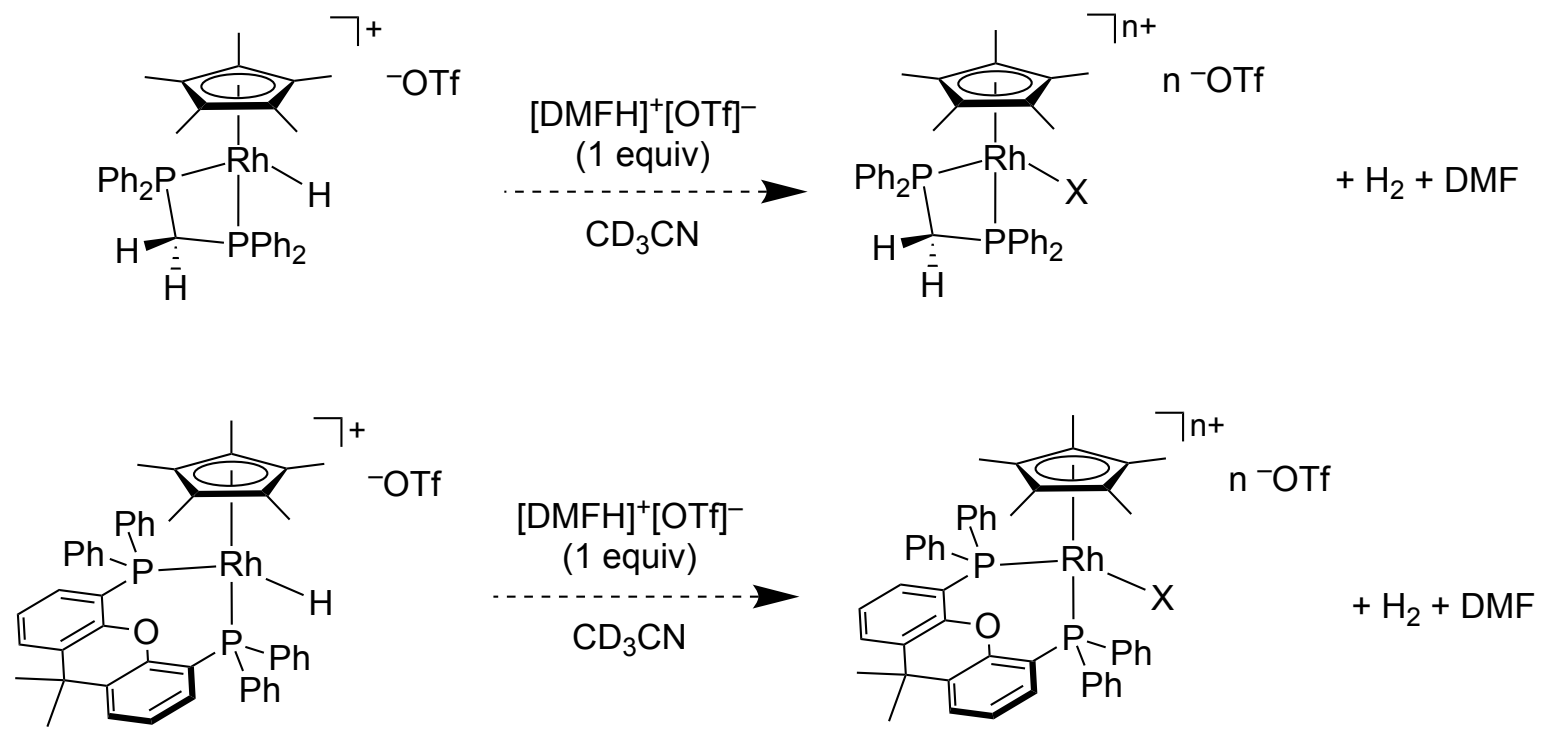

In an inert atmosphere glovebox, a J Young tube was charged with 5 or $6(12 \mu \mathrm{mol})$ and $1.5 \mathrm{~mL} \mathrm{CD}_{3} \mathrm{CN}$. A stock solution of [DMFH] ${ }^{+}[\mathrm{OTf}]^{-}$in $\mathrm{CD}_{3} \mathrm{CN}(0.023 \mathrm{M})$ was made, from which $0.5 \mathrm{~mL}(12 \mu \mathrm{mol})$ was added to each of the tubes. Each tube was capped quickly, brought out of the glovebox, and left to react at room temperature. ${ }^{1} \mathrm{H}$ NMR spectra were collected at various timepoints.

After 6 days, no reactivity was observed by NMR. At this point, each tube was placed in an oil bath heated to $65^{\circ} \mathrm{C}$ for an additional 48 hours. The stacked spectral data are provided below.

At the last timepoint in each set of stacked spectra below, a new, small triplet is present near the triplet of doublets corresponding to the $\mathrm{Cp}^{*}$ methyl protons of the monohydride. This new triplet is thought to indicate the presence of a new [Cp* $\mathrm{Rh}]$ complex (possibilities are shown in the figure above), possibly the result of hydrogen evolution, where $X$ can either be a bound triflate ligand $(n=1)$ or a bound acetonitrile $(n=2)$. Efforts towards rigorous characterization of this new species were not undertaken, as this species is only present at the level of $\sim 3 \%$ with respect to the hydride in each case. 

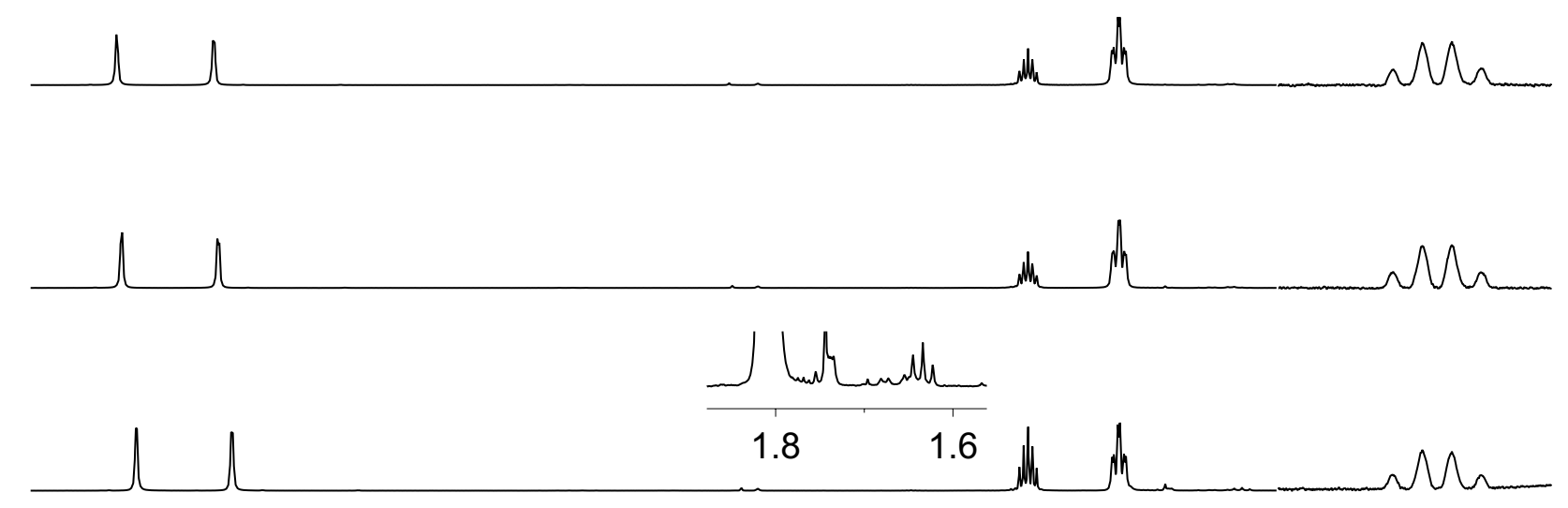

$\begin{array}{lllll}3.0 & 2.5 & 2.0 & -9.6 & -1 \mathrm{C}\end{array}$

Figure S36: Partial ${ }^{1} \mathrm{H}$ NMR spectra $\left(400 \mathrm{MHz}, \mathrm{CD}_{3} \mathrm{CN}\right)$ of $1: 1$ mixture of 5 and $[\mathrm{DMFH}]^{+}[\mathrm{OTf}]^{-}$in $\mathrm{CD}_{3} \mathrm{CN}$ after $30 \mathrm{~min}, 6$ days, and then heating for an additional 48 hours (from upper row to lower). The inset of the spectrum on the lowest row shows the new triplet. Hydride peak is not shown to scale.

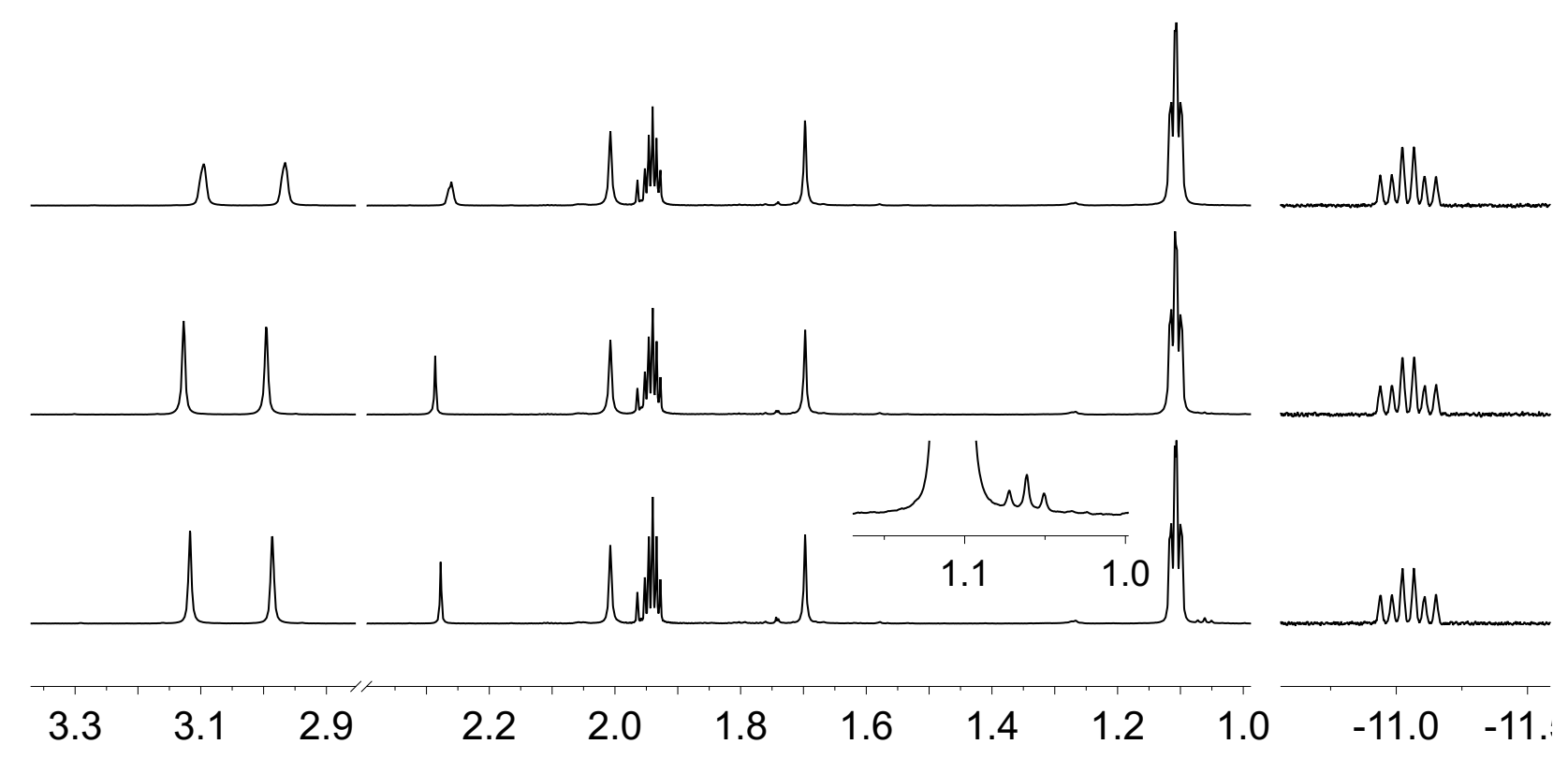

Figure S37: Partial ${ }^{1} \mathrm{H}$ NMR spectra $\left(400 \mathrm{MHz}, \mathrm{CD}_{3} \mathrm{CN}\right)$ of $1: 1$ mixture of 6 and $[\mathrm{DMFH}]^{+}[\mathrm{OTf}]^{-}$in $\mathrm{CD}_{3} \mathrm{CN}$ after $30 \mathrm{~min}, 6$ days, and then heating for an additional 48 hours (from upper row to lower row). The inset of the spectrum on the lowest row shows the new triplet. Hydride peak is not shown to scale. 


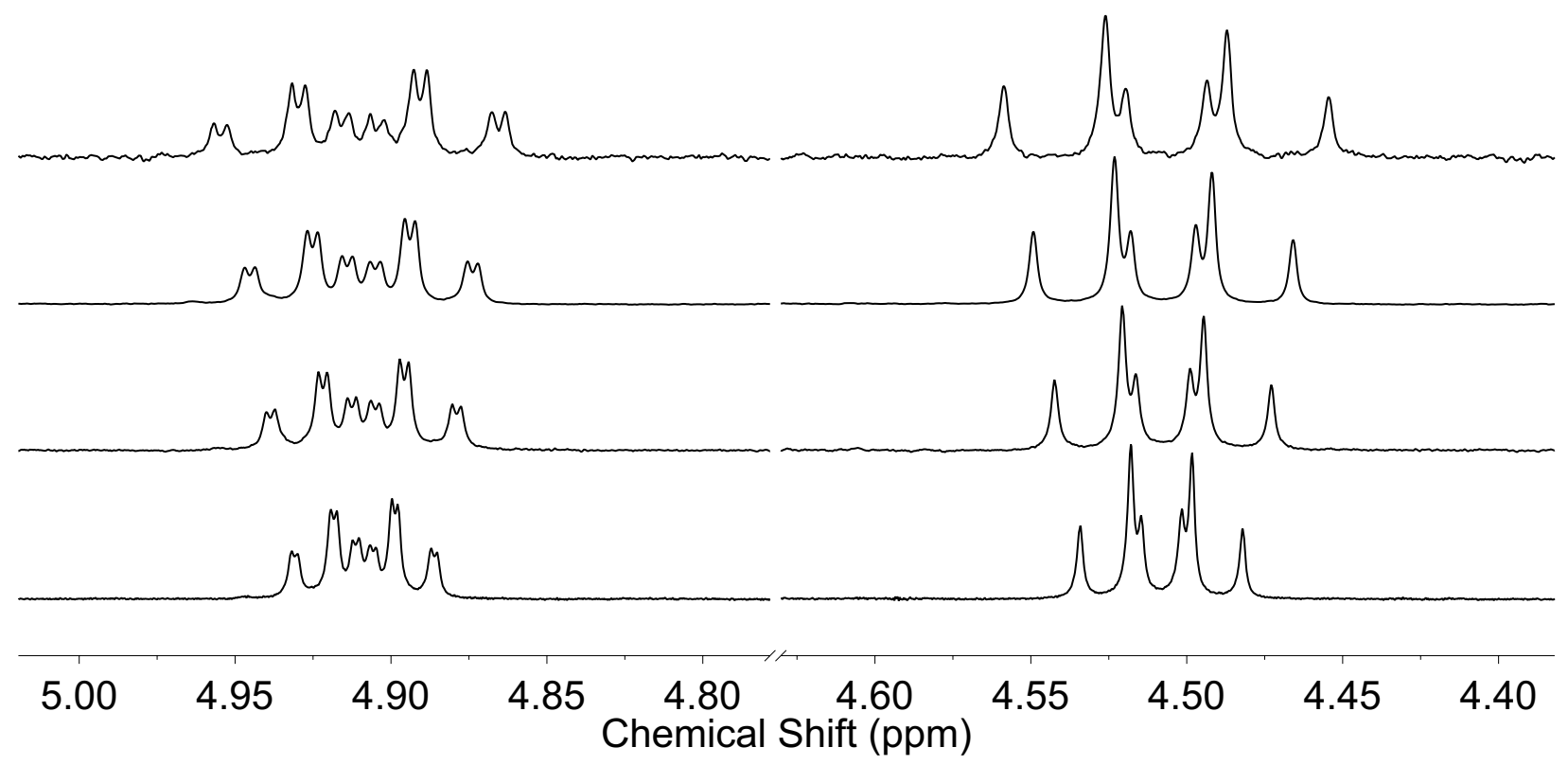

Figure S38: Partial ${ }^{1} \mathrm{H}$ NMR stack of 1 methylene proton resonances. From upper row to lower row: 400, 500, 600, and $800 \mathrm{MHz}$ spectrometer field strength.

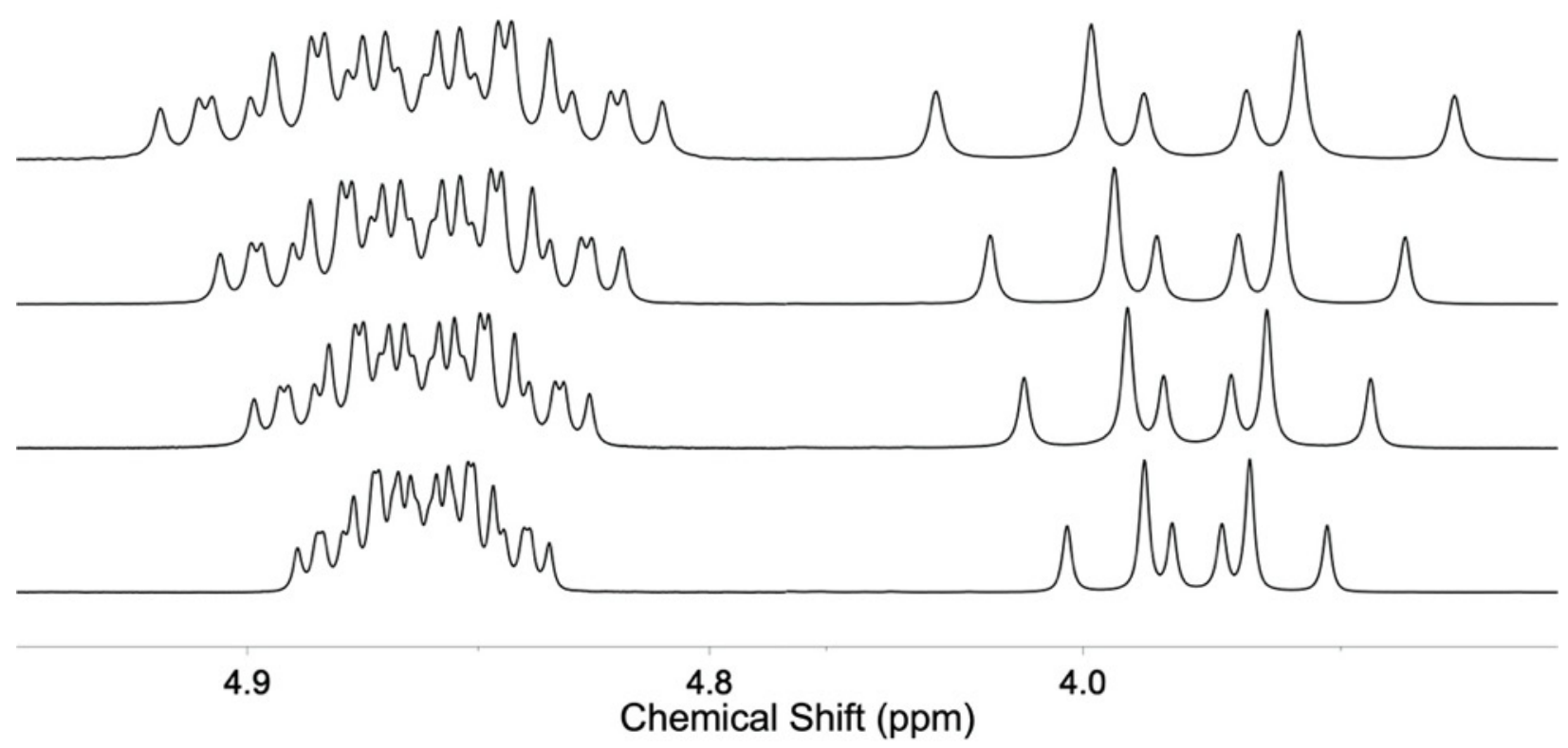

Figure S39: Partial ${ }^{1} \mathrm{H}$ NMR stack of 5 methylene proton resonances. From upper row to lower row: 400, 500, 600, and $800 \mathrm{MHz}$ spectrometer field strength. Resonances are not shown to scale. 


\section{${ }^{1}$ H NMR Digital Simulations}

\section{Simulation Details}

All ${ }^{1} \mathrm{H}$ NMR digital simulations were performed within MestReNova software using the Spin Simulation function. In all cases, for all non-proton nuclei included within the spin system, a chemical shift outside of the range of the simulation was assigned. This was done so that the coupling interactions between these nuclei and the proton nuclei of interest could be simulated without also simulating a peak for a non-proton nucleus. Example dialog boxes for simulating both $\mathbf{1}$ and $\mathbf{5}$ are provided below.
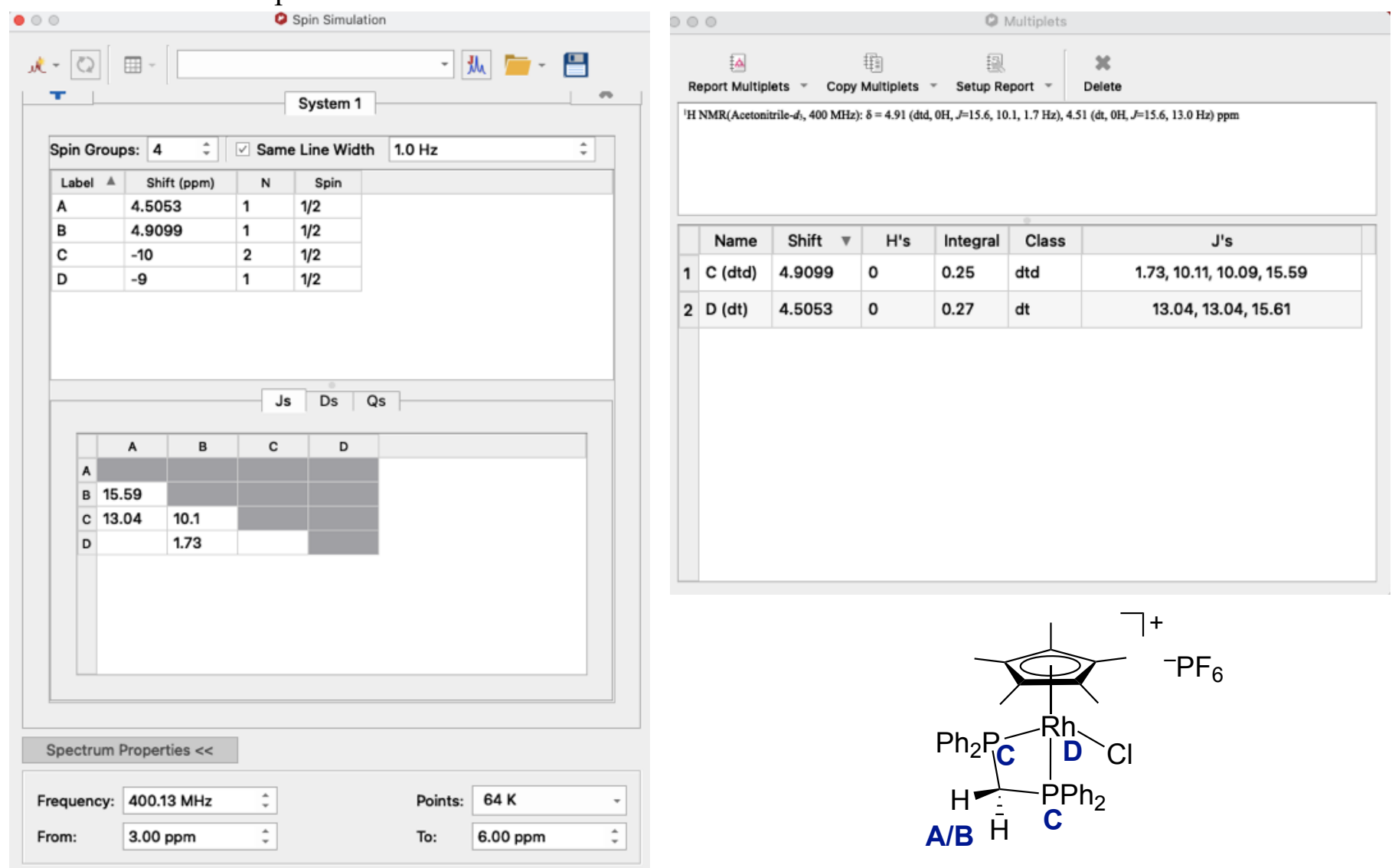

To conduct a simulation of $\mathbf{1}$, the number of spin groups was entered as 4 . The two methylene protons were assigned arbitrarily as $\mathrm{A}$ and $\mathrm{B}$, the two phosphorus nuclei were assigned as $\mathrm{C}$, and the rhodium metal center was assigned as D. In the first table, the experimental chemical shift of $\mathrm{A}$ and $\mathrm{B}$ were entered, as well as the number of each nucleus present $(\mathrm{N})$ and the spin of each nucleus (Spin); C and D were assigned outside-of-window chemical shifts, and the value for $\mathrm{N}$ and Spin were also included. Next, the experimental $J$ values were entered in the second table. Assigning $J$ values to the correct corresponding nuclei is critical for obtaining a simulated spectrum which resembles the experimental spectrum. Lastly, the Spectrum Properties dropdown allowed for insertion of the field frequency and the window of simulation. This frequency was adjusted for each multifrequency experimental spectrum obtained. For 1, the spectral data was simulated between 3.0-6.0 ppm, as only the methylene protons were of interest. 

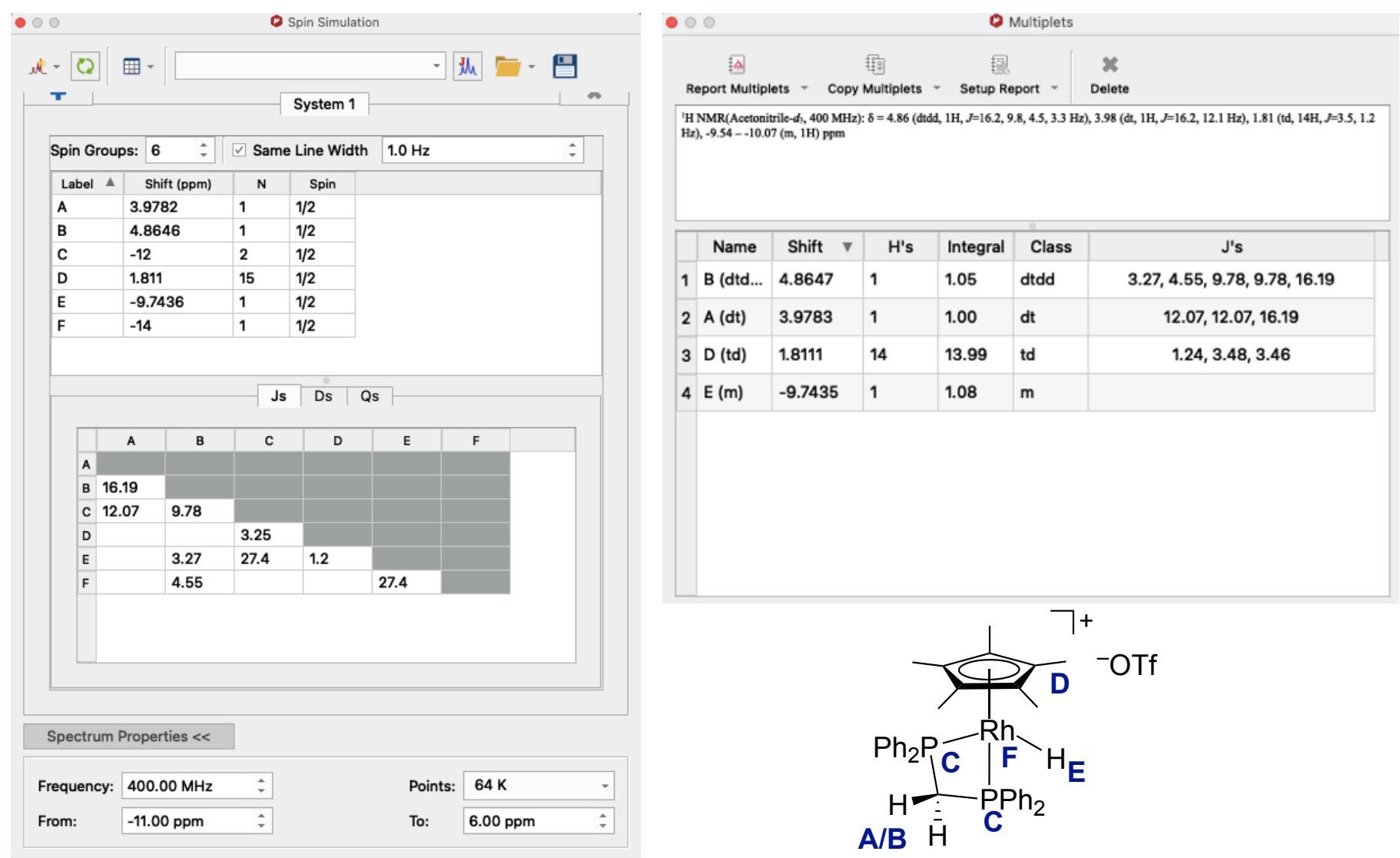

To conduct a simulation of $\mathbf{5}$, the number of spin groups was entered as 6 (as now, the $\mathrm{Cp}^{*}$ methyl protons and the hydride ligand were also included). The two methylene protons were assigned arbitrarily as $\mathrm{A}$ and $\mathrm{B}$, the two phosphorus nuclei were assigned as $\mathrm{C}$, the $\mathrm{Cp} \mathrm{p}^{*}$ methyl protons were assigned as D, the hydride ligand was assigned as $\mathrm{E}$, and the rhodium metal center was assigned as F. As in 1, the chemical shift and values of $\mathrm{N}$ and Spin were entered for each nucleus. Experimental $J$ values were entered; in this spin system, it was insightful to simulate a variety of different spectral data to understand the effects of coupling particularly between the $\mathrm{Cp}^{*}$ methyl protons and the hydride ligand. For 5, the spectral data was simulated between $-11.0-6.0 \mathrm{ppm}$, as the methylene protons, $\mathrm{Cp}^{*}$ methyl protons, and hydride ligand were of interest.

The hydride resonance is an apparent quartet $\left(\mathrm{q}_{\mathrm{app}}\right)$ in the experimental data, which is noticeably broadened as compared to a normal quartet. This broadness led to the software commonly labeling this resonance as a multiplet, thus preventing us from consistently determining precise coupling constants for this peak. The coupling constant of $27.4 \mathrm{~Hz}$ assigned to this resonance in the simulation above was obtained from a separate set of experimental data and applied here. Likewise, the broadness indicates the likelihood that some unobserved coupling interactions are present between the hydride and other nuclei, but are undeterminable from this specific, broadened qapp resonance. The following simulations probed these interactions. 


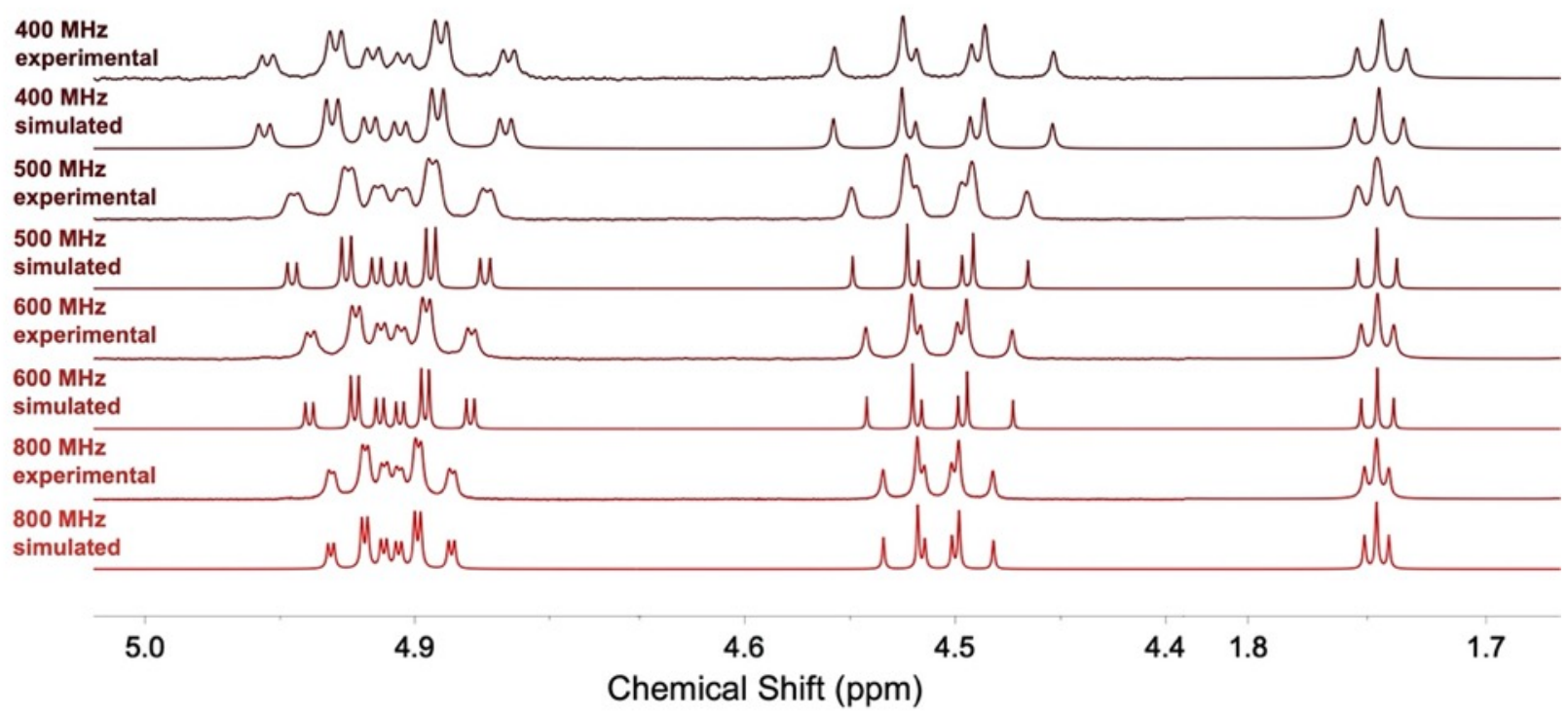

Figure S40: Stacked, partial multifrequency ${ }^{1} \mathrm{H}$ NMR spectra for 1, depicting alternating experimental and simulated spectra for both methylene protons and the $\mathrm{Cp}^{*}$ methyl protons (from left to right). Resonances are not shown to scale. 


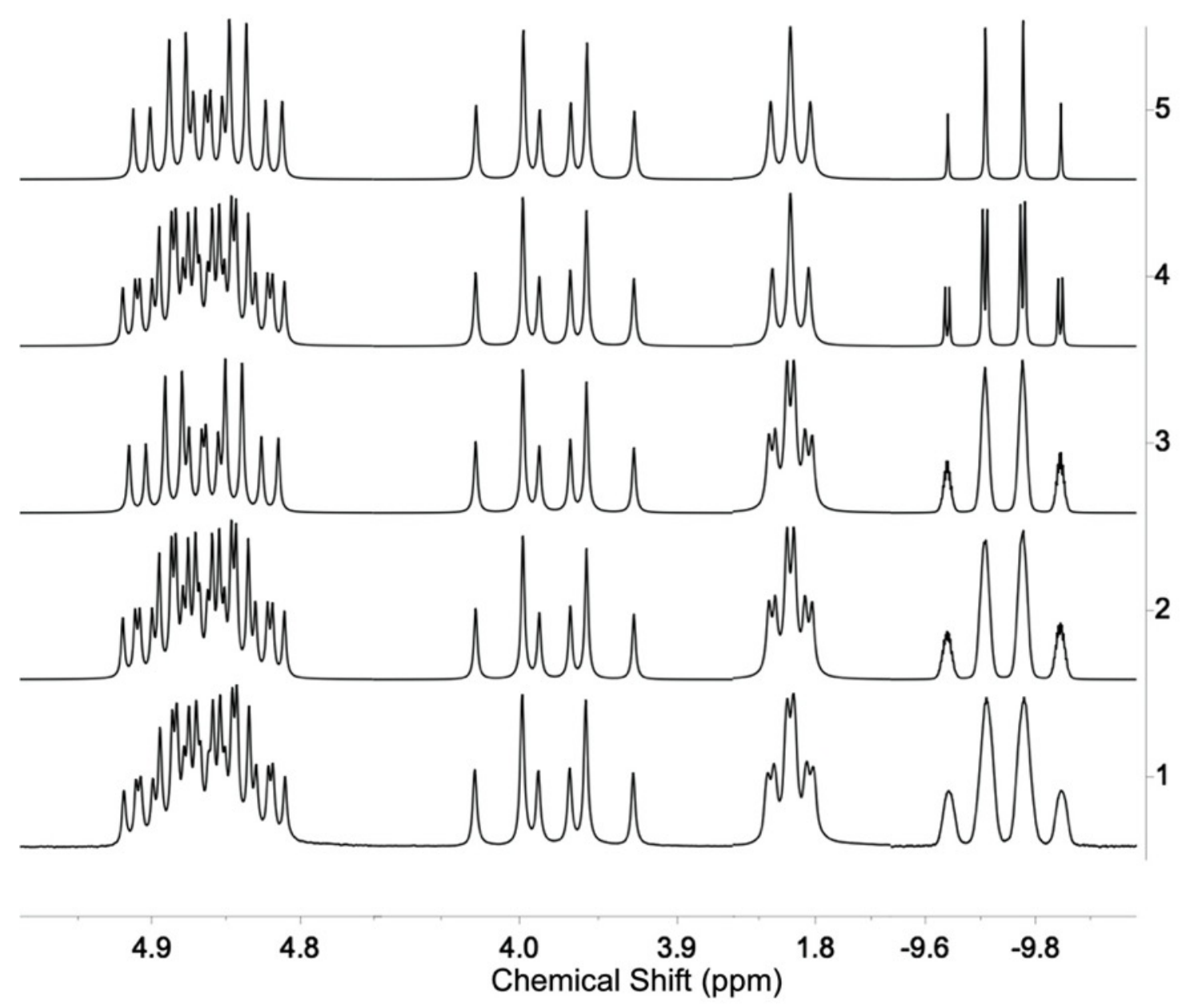

Figure S41: Stacked partial ${ }^{1} \mathrm{H}$ NMR spectra of 5 at $400 \mathrm{MHz}$ showing the experimental spectrum (lowest row, 1) and the simulated spectra (upper rows, 2-5) that resulted when changing coupling constant pairing assignments. Peaks are not to scale. Description of each spectrum below.

Spectrum 1: Experimental spectrum at $400 \mathrm{MHz}$

Spectrum 2: Simulated spectrum resulting from the dialog box (right), including hydride coupling to phosphorus, rhodium, $\mathrm{Cp}$ * methyl protons, and one methylene proton

Spectrum 3: Simulated spectrum, same as Spectrum 2 excluding $3.27 \mathrm{~Hz}$ coupling between hydride and methylene proton at 4.86 ppm

Spectrum 4: Simulated spectrum, same as Spectrum 2 excluding $1.24 \mathrm{~Hz}$ coupling between hydride and Cp* methyl protons at 1.81 ppm

Spectrum 5: Simulated spectrum, same as Spectrum 2 excluding both $3.27 \mathrm{~Hz}$ coupling between hydride and methylene proton and $1.24 \mathrm{~Hz}$ coupling between hydride and $\mathrm{Cp}^{*}$ methyl protons

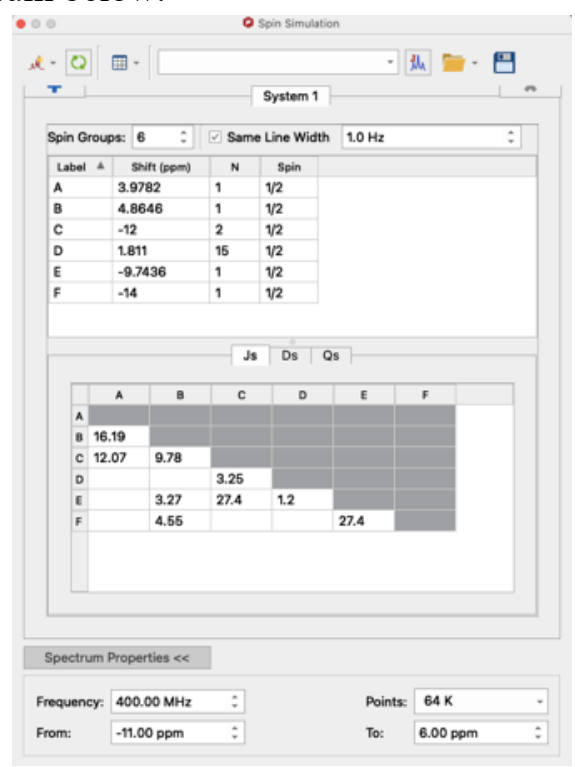




\section{Crystallographic Information}

\section{Refinement Details}

\section{X-ray Crystallographic Studies for 1 (v50e), 2 (v53e), 3 (v87e), 4 (q03I_ago), 5 (q88k), and 6 (q96k).}

Crystals of 1 (v50e), 2 (v53e), 3 (v87e), 4 (q031_ago), 5 (q88k), and $\mathbf{6}$ (q96k) were mounted with Paratone $\mathrm{N}$ oil in MiTeGen nylon loops under a cold stream and placed on a Bruker Proteum diffractometer equipped with two CCD detectors (Apex2 and Platinum 135) sharing a common Microstar microfocus $\mathrm{Cu}$ rotating anode generator running at $45 \mathrm{~mA}$ and $60 \mathrm{kV}(\mathrm{Cu} \mathrm{K \alpha}=1.54178 \AA)$. Complete sets of low temperature $(200 \mathrm{~K}) \mathrm{X}$-ray diffraction data were obtained for all six compounds using monochromated $\mathrm{Cu}$ radiation with the Apex 2 detector $(\mathbf{4}, \mathbf{5}$, and $\mathbf{6})$ positioned at $50.0 \mathrm{~mm}$ and equipped with Helios multilayer mirror optics or the Platinum 135 detector $(\mathbf{1}, \mathbf{2}$, and 3) positioned at $80.0 \mathrm{~mm}$ and equipped with Helios high-brilliance multilayer mirror optics. Totals of 2220 (1), 3324 (2), 2216 (3), 2292 (4), 1635 (5), and 1963 (6) $1.0^{\circ}$-wide $\omega$ - or $\phi$-scan frames were collected with counting times of 4-6 seconds (1-6).

Preliminary lattice constants were obtained with SMART in the Bruker Apex2 Software Suite. ${ }^{1}$ Integrated reflection intensities for all six compounds were produced using SAINT in the Bruker Apex2 Software Suite. ${ }^{1}$ Data sets for 1 (v50e), 2 (v53e), 3 (v87e), 4 (q031_ago) and 5 (q88k) were corrected empirically for variable absorption effects with SADABS ${ }^{2}$ using equivalent reflections; the data set for 6 (q96k) was corrected for variable absorption effects using a numerical face-indexed absorption correction. The Bruker software package SHELXTL was used to generate the initial .INS instruction file, and OLEX2 was then used to solve each structure using intrinsic phasing. Final stages of weighted full-matrix leastsquares refinement were conducted using $\mathrm{F}_{\mathrm{o}}{ }^{2}$ data with SHELXTL ${ }^{3}$ or the OLEX2 software package equipped with XL. ${ }^{4}$ The relevant crystallographic and structure refinement data for all six structures are given in Table $\mathrm{S} 1$.

The final structural model for each structure incorporated anisotropic thermal parameters for all fulloccupancy, non-hydrogen atoms. All non-hydride hydrogen atoms were included in the model at geometrically calculated positions and refined using a riding model. Non-methyl hydrogen atoms were fixed at idealized riding model $\mathrm{sp}^{2}$ - or $\mathrm{sp}^{3}$-hybridized positions with $\mathrm{C}-\mathrm{H}$ bond lengths of $0.95-0.99 \AA$. Hydrogen atoms for the $\mathrm{Cp}^{*}$ methyl groups in $\mathbf{3}$ were located from a difference Fourier and their fractional atomic coordinates were allowed to vary in least squares refinement cycles. Methyl groups for the remaining Cp* ligands, Xantphos ligands, and acetonitrile molecules of crystallization were incorporated into the structural model as idealized $\mathrm{sp}^{3}$-hybridized rigid rotors with $\mathrm{C}-\mathrm{H}$ bond lengths of $0.98 \AA$ that were allowed to rotate freely about their $\mathrm{C}-\mathrm{C}$ bonds in least-squares refinement cycles. The toluene methyl groups for $\mathbf{4}$ were fixed at idealized staggered positions. Hydride hydrogen atoms in $\mathbf{5}$ and $\mathbf{6}$ were located from difference Fouriers and included in the structural model as independent isotropic atoms whose parameters were allowed to vary in least-squares refinement cycles. 
Table S1: Crystal Refinement Data

\begin{tabular}{|c|c|c|c|}
\hline & $\mathbf{1}(\mathrm{v} 50 \mathrm{e})$ & $2(\mathrm{v} 53 \mathrm{e})$ & $3(\mathrm{v} 87 \mathrm{e})$ \\
\hline CCDC accession code & 2044718 & 2044719 & 2067364 \\
\hline Empirical formula & $\mathrm{C}_{37} \mathrm{H}_{40} \mathrm{ClF}_{6} \mathrm{NP}_{3} \mathrm{Rh}$ & $\mathrm{C}_{50} \mathrm{H}_{49} \mathrm{Cl}_{3} \mathrm{~F}_{6} \mathrm{OP}_{3} \mathrm{Rh}$ & $\mathrm{C}_{35} \mathrm{H}_{37} \mathrm{P}_{2} \mathrm{Rh}$ \\
\hline Formula weight & 843.97 & 1082.06 & 622.49 \\
\hline Temperature & $200 \mathrm{~K}$ & $200 \mathrm{~K}$ & $200 \mathrm{~K}$ \\
\hline Wavelength & $1.54178 \AA$ & $1.54178 \AA$ & $1.54178 \AA$ \\
\hline Crystal system & monoclinic & triclinic & monoclinic \\
\hline Space group & $C 2$ (No. 5) & $P-1$ (No. 2) & $P 2_{1} / n($ No. 14$)$ \\
\hline $\mathbf{a}$ & $22.5645(10) \AA$ & $10.8320(4) \AA$ & $9.0090(4) \AA$ \\
\hline $\mathbf{b}$ & $8.6211(4) \AA$ & $20.8901(8) \AA$ & 8.9292(4) $\AA$ \\
\hline c & $22.3120(10) \AA$ & $21.2052(8) \AA$ & $36.9176(17) \AA$ \\
\hline$\alpha$ & $90^{\circ}$ & $97.7441(10)^{\circ}$ & $90^{\circ}$ \\
\hline $\boldsymbol{\beta}$ & $119.2692(10)^{\circ}$ & $93.2743(11)^{\circ}$ & $91.606(2)^{\circ}$ \\
\hline$\gamma$ & $90^{\circ}$ & $91.0432(10)^{\circ}$ & $90^{\circ}$ \\
\hline Volume & $3786.2(3) \AA^{3}$ & $4745.2(3) \AA^{3}$ & $2968.6(2) \AA^{3}$ \\
\hline $\mathbf{Z}$ & 4 & 4 & 4 \\
\hline Density (calculated) & $1.481 \mathrm{~g} / \mathrm{cm}^{3}$ & $1.515 \mathrm{~g} / \mathrm{cm}^{3}$ & $1.393 \mathrm{~g} / \mathrm{cm}^{3}$ \\
\hline Absorption coefficient & $5.989 \mathrm{~mm}^{-1}$ & $5.941 \mathrm{~mm}^{-1}$ & $5.825 \mathrm{~mm}^{-1}$ \\
\hline $\mathbf{F}(000)$ & 1720 & 2208 & 1288 \\
\hline Crystal size & $0.21 \times 0.08 \times 0.045 \mathrm{~mm}^{3}$ & $0.12 \times 0.10 \times 0.09 \mathrm{~mm}^{3}$ & $0.185 \times 0.075 \times 0.075 \mathrm{~mm}^{3}$ \\
\hline Number of data frames/time & 2220/4-6 seconds & 3324/4-6 seconds & 2216/4-6 seconds \\
\hline Theta range & 5.60 to $68.35^{\circ}$ & 2.11 to $68.39^{\circ}$ & 4.79 to $68.33^{\circ}$ \\
\hline Index ranges & $\begin{array}{l}-26 \leq \mathrm{h} \leq 26,-7 \leq \mathrm{k} \leq 10,-25 \leq 1 \leq \\
26\end{array}$ & $\begin{array}{l}-12 \leq \mathrm{h} \leq 13,-25 \leq \mathrm{k} \leq 20,-25 \\
\leq 1 \leq 24\end{array}$ & $\begin{array}{l}-10 \leq \mathrm{h} \leq 10,-7 \leq \mathrm{k} \leq 10,-44 \leq \\
1 \leq 43\end{array}$ \\
\hline Reflections collected & 12133 & 43756 & 19379 \\
\hline Independent reflections & $4847\left[\mathrm{R}_{\mathrm{int}}=0.032, \mathrm{Rsigma}=0.048\right]$ & $\begin{array}{l}16483\left[\mathrm{R}_{\text {int }}=0.029, \text { Rsigma }=\right. \\
0.033]\end{array}$ & $\begin{array}{l}5311\left[\mathrm{R}_{\text {int }}=0.029, \text { Rsigma }=\right. \\
0.029]\end{array}$ \\
\hline Completeness $/ \boldsymbol{\theta}_{\max }$ & $98.5 \% / 66.00^{\circ}$ & $97.5 \% / 66.00^{\circ}$ & $98.6 \% / 67.68^{\circ}$ \\
\hline Absorption correction & Multi-scan & Multi-scan & Multi-scan \\
\hline Max. and min. transmission & 1.000 and 0.638 & 1.000 and 0.873 & 1.000 and 0.876 \\
\hline Refinement method & Full-matrix least-squares on $\mathrm{F}^{2}$ & Full-matrix least-squares on $\mathrm{F}^{2}$ & Full-matrix least-squares on $\mathrm{F}^{2}$ \\
\hline Data / restraints / parameters & 4847 / 1 / 452 & 16483 / 6 / 1167 & $5311 / 0 / 389$ \\
\hline Goodness-of-fit on $\mathbf{F}^{2}$ & 1.025 & 1.024 & 1.046 \\
\hline Final $R$ indices $[I>2 \sigma(I)]$ & $\mathrm{R}_{1}=0.033, \mathrm{wR}_{2}=0.085$ & $\mathrm{R}_{1}=0.042, \mathrm{wR}_{2}=0.108$ & $\mathrm{R}_{1}=0.025, \mathrm{wR}_{2}=0.060$ \\
\hline $\mathbf{R}$ indices (all data) & $\mathrm{R} 1=0.035, \mathrm{wR}_{2}=0.085$ & $\mathrm{R}_{1}=0.046, \mathrm{wR}_{2}=0.111$ & $\mathrm{R}_{1}=0.027, \mathrm{wR}_{2}=0.061$ \\
\hline Largest diff. peak and hole & 0.41 and $-0.85 \mathrm{e}^{-} / \AA^{3}$ & 1.29 and $-1.42 \mathrm{e}^{-} / \AA^{3}$ & 0.30 and $-0.39 \mathrm{e}^{-} / \AA^{3}$ \\
\hline
\end{tabular}




\begin{tabular}{|c|c|c|c|}
\hline & 4 (q031_ago) & $5(q 88 k)$ & $6(q 96 k)$ \\
\hline CCDC accession code & 2067366 & 2067363 & 2067365 \\
\hline Empirical formula & $\mathrm{C}_{54.25} \mathrm{H}_{53} \mathrm{OP}_{2} \mathrm{Rh}$ & $\mathrm{C}_{36} \mathrm{H}_{38} \mathrm{~F}_{3} \mathrm{O}_{3} \mathrm{P}_{2} \mathrm{RhS}$ & $\mathrm{C}_{50} \mathrm{H}_{48} \mathrm{~F}_{3} \mathrm{O}_{4} \mathrm{P}_{2} \mathrm{RhS}$ \\
\hline Formula weight & 885.81 & 772.57 & 966.79 \\
\hline Temperature & $200 \mathrm{~K}$ & $200 \mathrm{~K}$ & $200 \mathrm{~K}$ \\
\hline Wavelength & $1.54178 \AA$ & $1.54178 \AA$ & $1.54178 \AA$ \\
\hline Crystal system & monoclinic & orthorhombic & orthorhombic \\
\hline Space group & $C 2 / c$ (No. 15$)$ & Pnma (No. 62) & $\mathrm{Pca}_{1}$ (No. 29) \\
\hline $\mathbf{a}$ & $29.5173(4) \AA$ & $18.8596(3) \AA$ & $22.4478(6) \AA$ \\
\hline $\mathbf{b}$ & $18.4213(3) \AA$ & $18.9169(3) \AA$ & $11.2787(3) \AA$ \\
\hline c & $22.0747(3) \AA$ & $9.7134(2) \AA$ & $34.9472(10) \AA$ \\
\hline$\alpha$ & $90^{\circ}$ & $90^{\circ}$ & $90^{\circ}$ \\
\hline$\beta$ & $127.4030(10)$ & $90^{\circ}$ & $90^{\circ}$ \\
\hline$\gamma$ & $90^{\circ}$ & $90^{\circ}$ & $90^{\circ}$ \\
\hline Volume & $9535.0(3) \AA^{3}$ & $3465.40(11) \AA^{3}$ & $8848.0(4) \AA^{3}$ \\
\hline $\mathbf{Z}$ & 8 & 4 & 8 \\
\hline Density (calculated) & $1.234 \mathrm{~g} / \mathrm{cm}^{3}$ & $1.481 \mathrm{~g} / \mathrm{cm}^{3}$ & $1.452 \mathrm{~g} / \mathrm{cm}^{3}$ \\
\hline Absorption coefficient & $3.799 \mathrm{~mm}^{-1}$ & $5.852 \mathrm{~mm}^{-1}$ & $4.726 \mathrm{~mm}^{-1}$ \\
\hline $\mathbf{F}(000)$ & 3692 & 1584 & 3984 \\
\hline Crystal size & $0.085 \times 0.03 \times 0.02 \mathrm{~mm}^{3}$ & $0.065 \times 0.055 \times 0.05 \mathrm{~mm}^{3}$ & $0.216 \times 0.071 \times 0.04 \mathrm{~mm}^{3}$ \\
\hline Number of data frames/time & 2292/4-6 seconds & 1635/4-6 seconds & 1963/4-6 seconds \\
\hline Theta range & 3.05 to $70.18^{\circ}$ & 4.69 to $70.06^{\circ}$ & 2.53 to $70.18^{\circ}$ \\
\hline Index ranges & $\begin{array}{l}-35 \leq \mathrm{h} \leq 35,-19 \leq \mathrm{k} \leq 21,-26 \leq 1 \leq \\
26\end{array}$ & $\begin{array}{l}-22 \leq \mathrm{h} \leq 19,-22 \leq \mathrm{k} \leq 19,-11 \\
\leq 1 \leq 11\end{array}$ & $\begin{array}{l}-26 \leq \mathrm{h} \leq 24,-13 \leq \mathrm{k} \leq 11,-41 \\
\leq 1 \leq 40\end{array}$ \\
\hline Reflections collected & 33394 & 12431 & 41479 \\
\hline Independent reflections & $8645\left[\mathrm{R}_{\text {int }}=0.034, \mathrm{R}_{\text {sigma }}=0.028\right]$ & $\begin{array}{l}3260\left[\mathrm{R}_{\text {int }}=0.033, \mathrm{R}_{\text {sigma }}=\right. \\
0.027]\end{array}$ & $\begin{array}{l}13475\left[\mathrm{R}_{\text {int }}=0.031, \mathrm{R}_{\text {sigma }}=\right. \\
0.046]\end{array}$ \\
\hline Completeness $/ \boldsymbol{\theta}_{\max }$ & $97.9 \% / 67.68^{\circ}$ & $98.9 \% / 66.00^{\circ}$ & $99.6 \% / 66.00^{\circ}$ \\
\hline Absorption correction & Multi-scan & Multi-scan & Numerical face-indexed \\
\hline Max. and min. transmission & 1.000 and 0.784 & 1.000 and 0.764 & 1.000 and 0.354 \\
\hline Refinement method & Full-matrix least-squares on $\mathrm{F}^{2}$ & Full-matrix least-squares on $\mathrm{F}^{2}$ & Full-matrix least-squares on $\mathrm{F}^{2}$ \\
\hline Data / restraints / parameters & $8645 / 13 / 517$ & $3260 / 0 / 226$ & 13475 / 1 / 1122 \\
\hline Goodness-of-fit on $F^{2}$ & 1.049 & 1.076 & 1.023 \\
\hline Final $R$ indices $[I>2 \sigma(I)]$ & $\mathrm{R}_{1}=0.037, \mathrm{wR}_{2}=0.113$ & $\mathrm{R}_{1}=0.032, \mathrm{wR}_{2}=0.081$ & $\mathrm{R}_{1}=0.024, \mathrm{wR}_{2}=0.058$ \\
\hline $\mathbf{R}$ indices (all data) & $\mathrm{R}_{1}=0.043, \mathrm{wR}_{2}=0.120$ & $\mathrm{R}_{1}=0.033, \mathrm{wR}_{2}=0.082$ & $\mathrm{R}_{1}=0.025, \mathrm{wR}_{2}=0.062$ \\
\hline Largest diff. peak and hole & 1.13 and $-0.47 \mathrm{e}^{-} / \AA^{3}$ & 0.53 and $-0.48 \mathrm{e}^{-} / \AA^{3}$ & 0.60 and $-0.38 \mathrm{e}^{-} / \AA^{3}$ \\
\hline
\end{tabular}




\section{Special Refinement Details for 1}

Complex 1 crystallizes in the monoclinic space group C2. The crystal was refined as a twocomponent inversion twin with the first component comprising $96.7 \%$ and the second component comprising 3.3\%. The secondary methylene group was refined using riding coordinates. There are two crystallographically-independent outer-sphere hexafluorophosphate counterianions. Both utilize a crystallographic $\mathrm{C}_{2}$ axis and are therefore included in the structural model with occupancy factors of 0.50 . Each one accounts for a formal negative charge of $-1 / 2$ in the asymmetric unit. 


\section{Solid-State Structure of Molecular Cation of Compound 1}

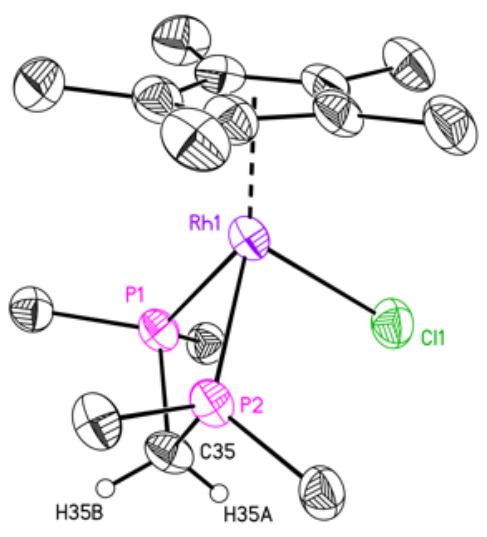

Figure S42: Solid-state structure for the core of the molecular cation in the asymmetric unit of 1. The hexafluorophosphate counteranions (each having an occupancy of 0.5 , vide supra), a cocrystallized acetonitrile molecule, all hydrogen atoms except for $\mathrm{H} 35 \mathrm{~A}$ and $\mathrm{H} 35 \mathrm{~B}$, and the additional atoms associated with the phosphine phenyl rings are omitted for clarity. Displacement ellipsoids are shown at the $50 \%$ probability level.

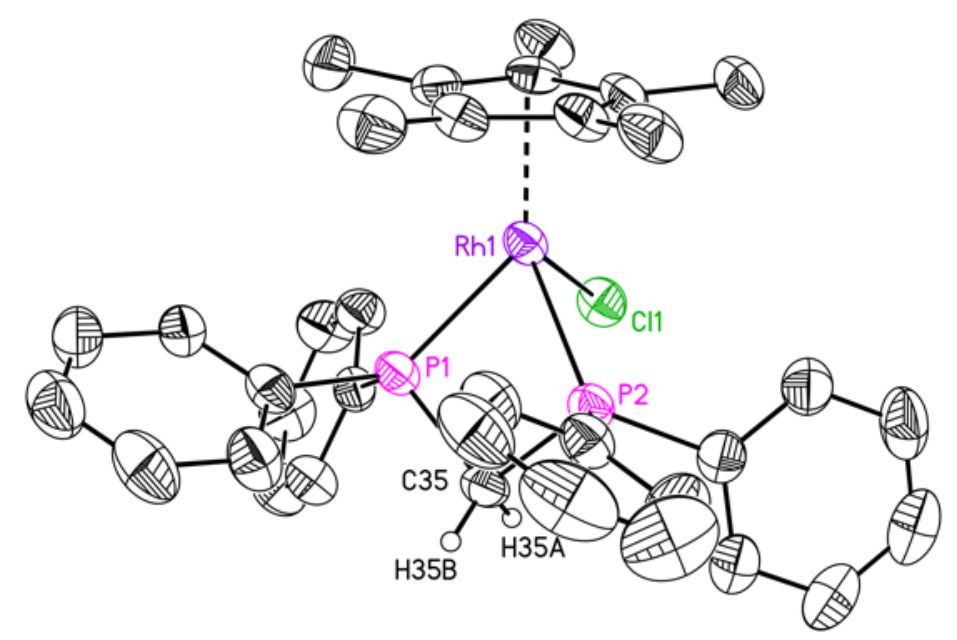

Figure S43: Solid-state structure of the molecular cation in the asymmetric unit of 1. The hexafluorophosphate counteranions and a co-crystallized acetonitrile molecule are omitted for clarity, as are all hydrogen atoms except for H35A and H35B. Displacement ellipsoids are shown at the $50 \%$ probability level. 


\section{Full Asymmetric Unit of 1}
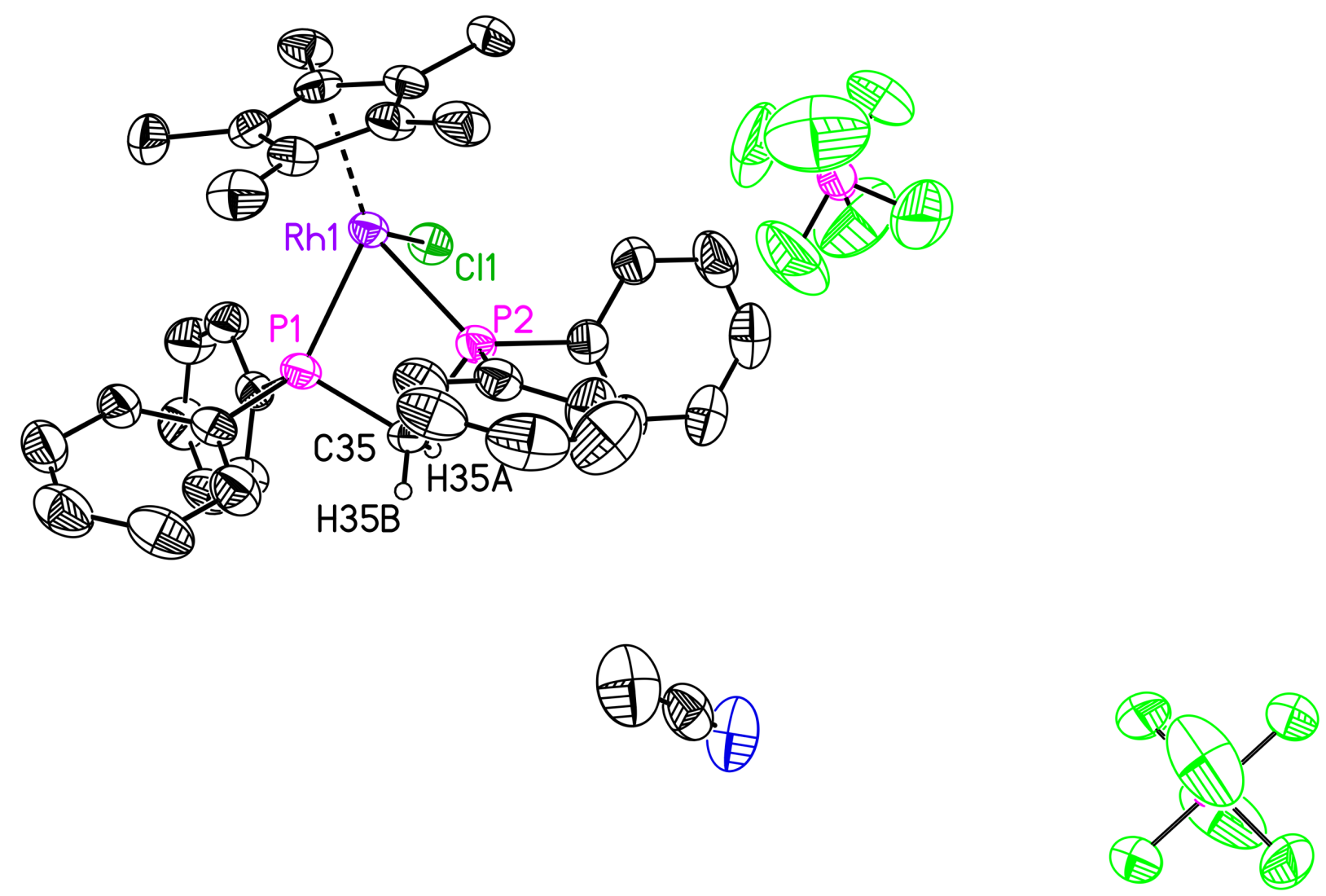

Figure S44: Solid-state structure for the asymmetric unit of 1. All hydrogen atoms, except H35A and $\mathrm{H} 35 \mathrm{~B}$, are omitted for clarity. There are two crystallographically-independent outer-sphere hexafluorophosphate counterianions. Both utilize a crystallographic $\mathrm{C}_{2}$ axis and are therefore included in the structural model with occupancy factors of 0.50 . Each one accounts for a formal negative charge of $-1 / 2$ in the asymmetric unit. Displacement ellipsoids are shown at the $50 \%$ probability level. 


\section{Special Refinement Details for 2}

Complex 2 crystallizes in the triclinic space group $P-1$. Mild ISOR restraints (in OLEX2) were applied to the anisotropic displacement ellipsoid of $\mathrm{C} 27$. 


\section{Solid-State Structure of First Molecular Cation in 2}

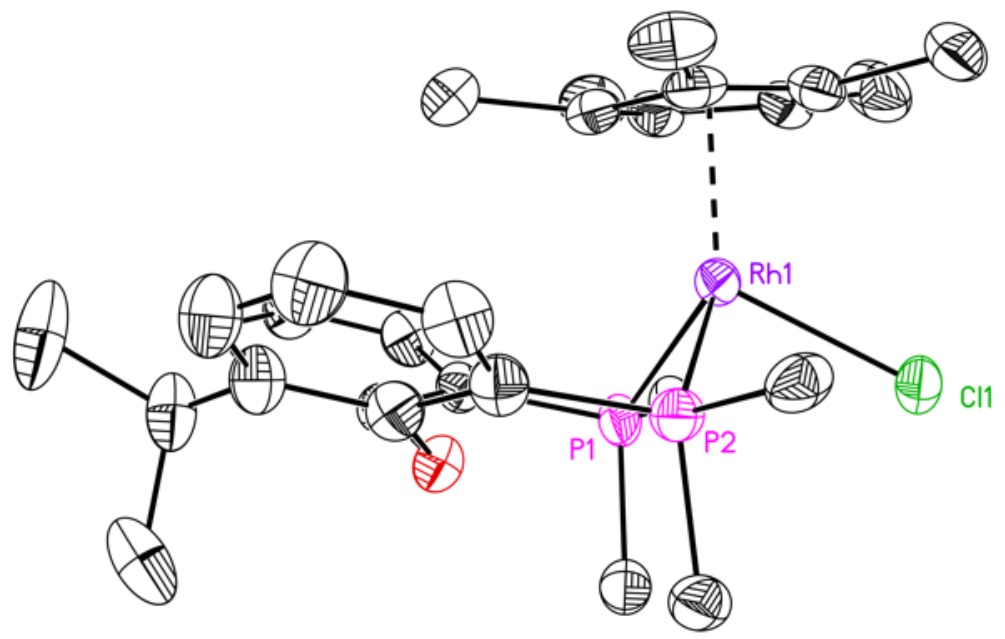

Figure S45: Solid-state structure for the non-hydrogen core for the first of two crystallographically-independent and virtually identical molecular cations in the asymmetric unit of 2. A second molecular cation of $\mathbf{2}$, two co-crystallized hexafluorophosphate counteranions, and two co-crystallized dichloromethane molecules are omitted for clarity, as are all hydrogen atoms and additional atoms for the phosphine phenyl rings. Displacement ellipsoids are shown at the $50 \%$ probability level.

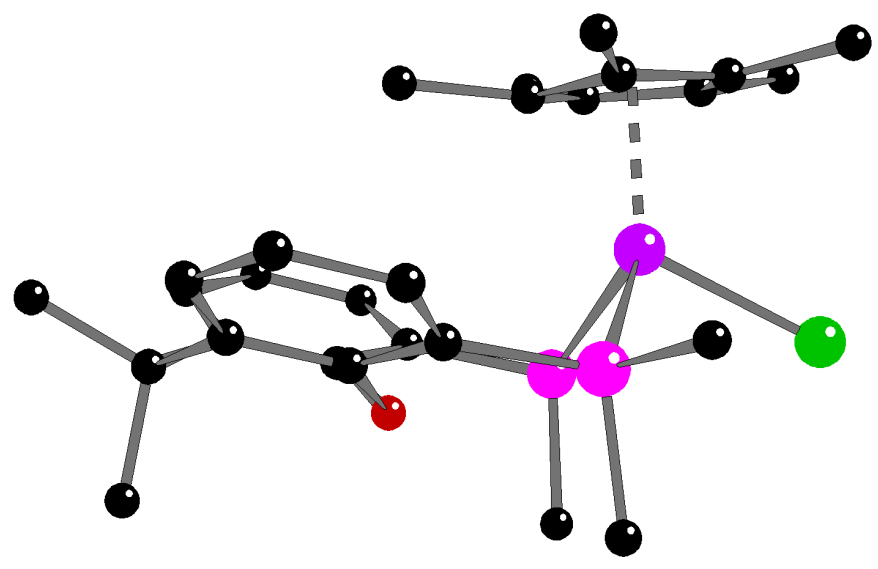

Figure S46: Ball-and-stick representation for the non-hydrogen core for the first of two crystallographically-independent and virtually identical molecular cations in the asymmetric unit of 2. A second molecular cation of $\mathbf{2}$, two co-crystallized hexafluorophosphate counteranions and two co-crystallized dichloromethane molecules are omitted for clarity as are all hydrogen atoms and additional atoms for the phosphine phenyl rings. 


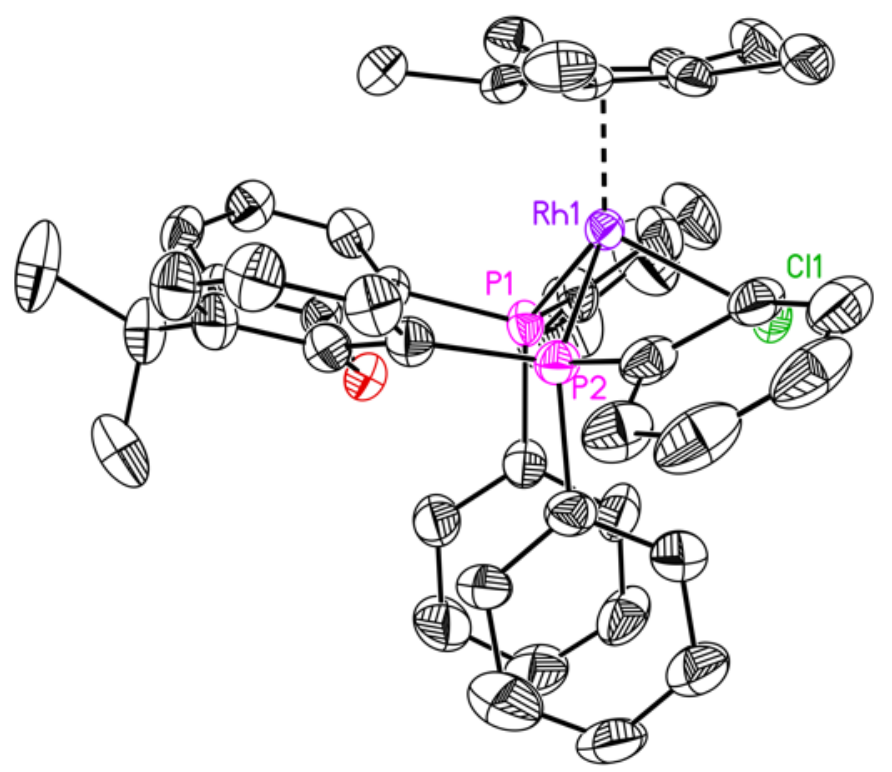

Figure S47: Solid-state structure for the non-hydrogen atoms for the first of two crystallographically-independent and virtually identical molecular cations in the asymmetric unit of $\mathbf{2}$. A second molecular cation of $\mathbf{2}$, two co-crystallized hexafluorophosphate counteranions and two co-crystallized dichloromethane molecules are omitted for clarity. All hydrogen atoms are also omitted for clarity. Displacement ellipsoids are shown at the 50\% probability level.

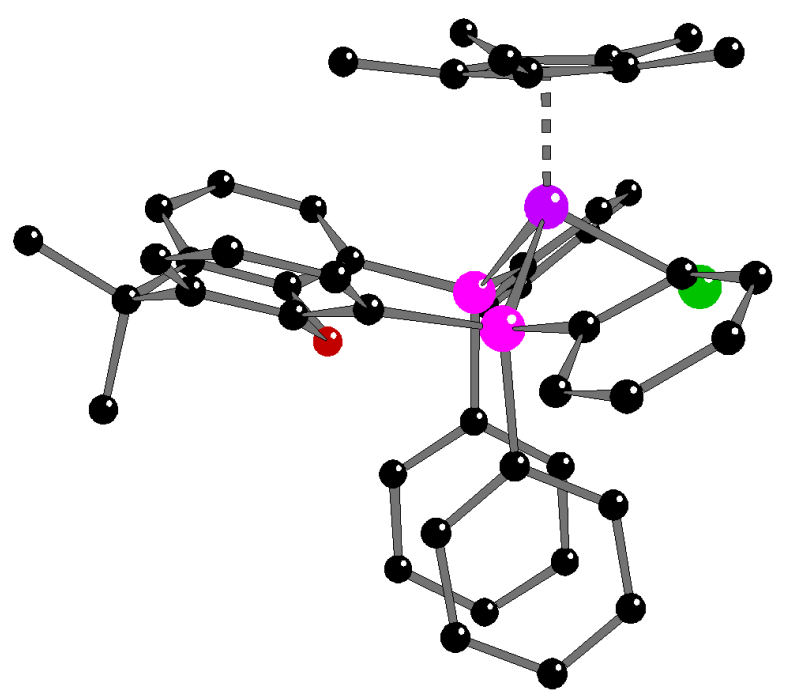

Figure S48: Ball-and-stick representation for the non-hydrogen atoms for the first of two crystallographically-independent and virtually identical molecular cations in the asymmetric unit of 2. A second molecular cation of $\mathbf{2}$, two co-crystallized hexafluorophosphate counteranions and two co-crystallized dichloromethane molecules are omitted for clarity, as are all hydrogen atoms. 


\section{Full Solid-State Asymmetric Unit for 2}
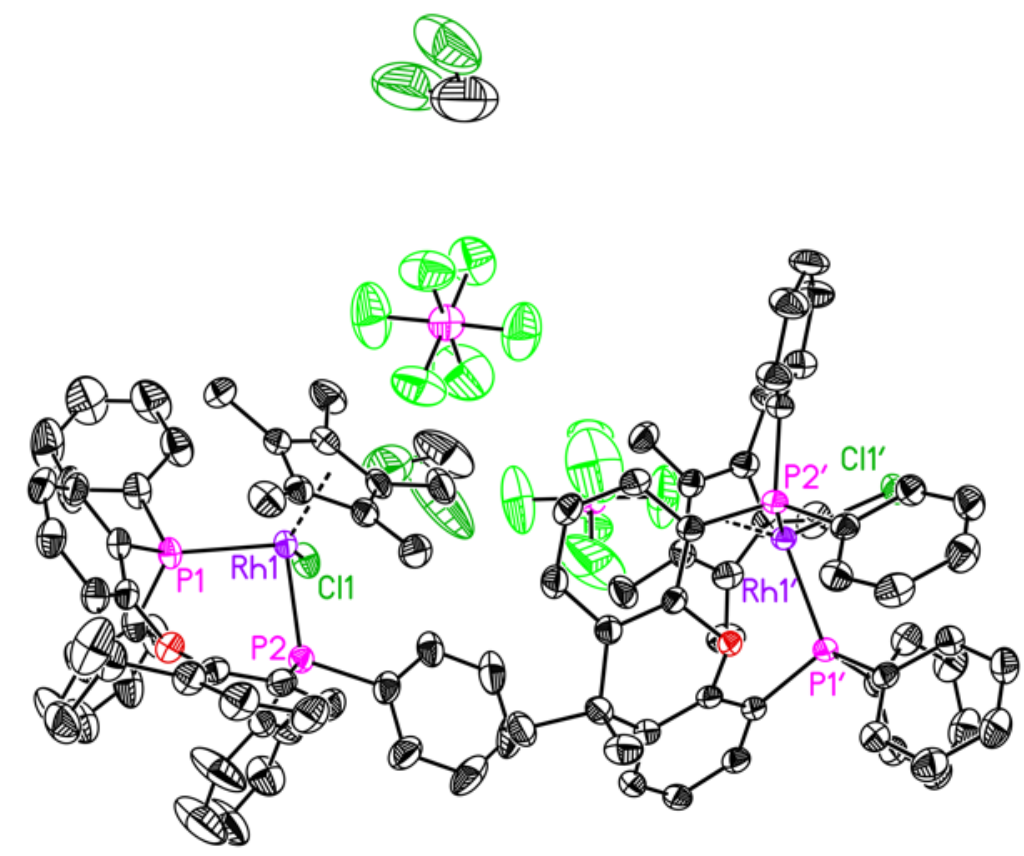

Figure S49: Full solid-state asymmetric unit for 2. Atoms of the second crystallographicallyindependent cation are labeled with a prime ('). Hydrogen atoms are omitted for clarity. Displacement ellipsoids are shown at the 50\% probability level.

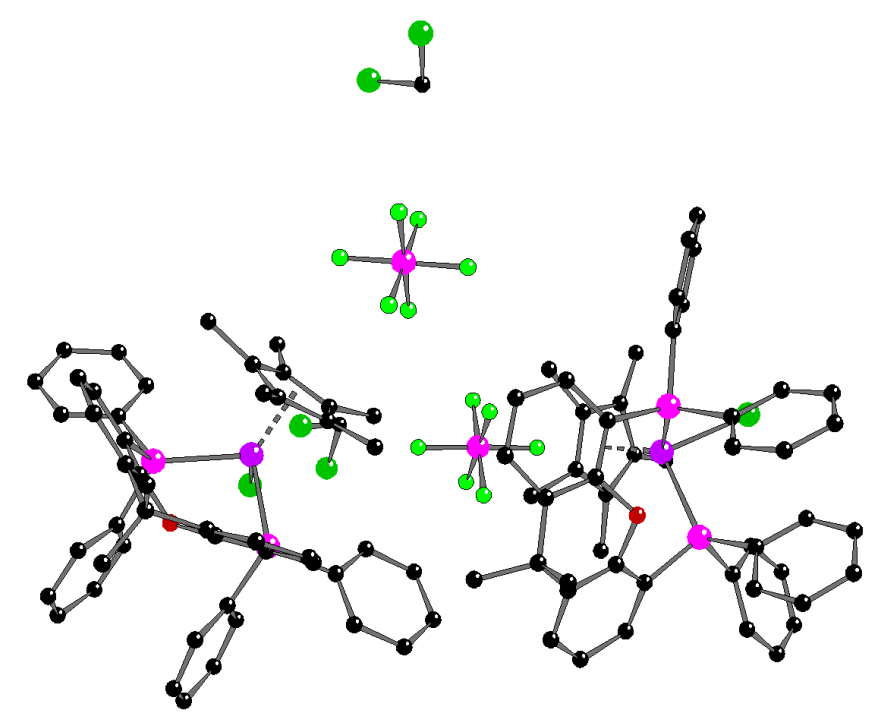

Figure S50: Ball-and-stick representation for the solid-state asymmetric unit of 2. Hydrogen atoms are omitted for clarity. 


\section{Special Refinement Details for 3}

No special refinement was required.

\section{Solid-State Structure of 3}

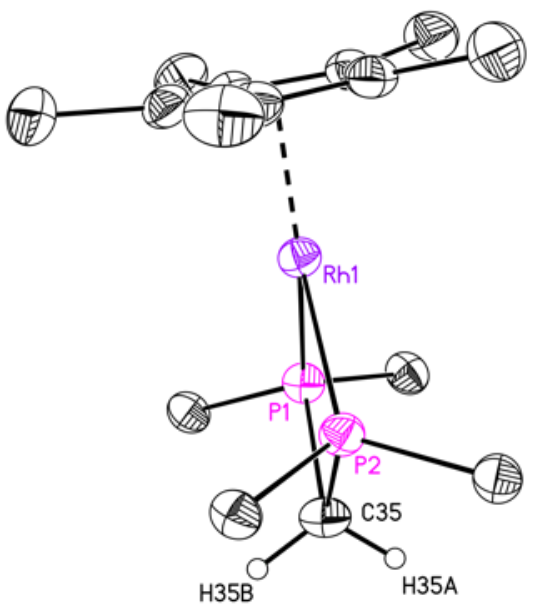

Figure S51: Structure of the molecular core for the asymmetric unit in crystals of 3. All hydrogen atoms except for $\mathrm{H} 35 \mathrm{~A}$ and $\mathrm{H} 35 \mathrm{~B}$ and additional atoms for the phosphine phenyl rings are deleted for clarity. Displacement ellipsoids are shown at the 50\% probability level.

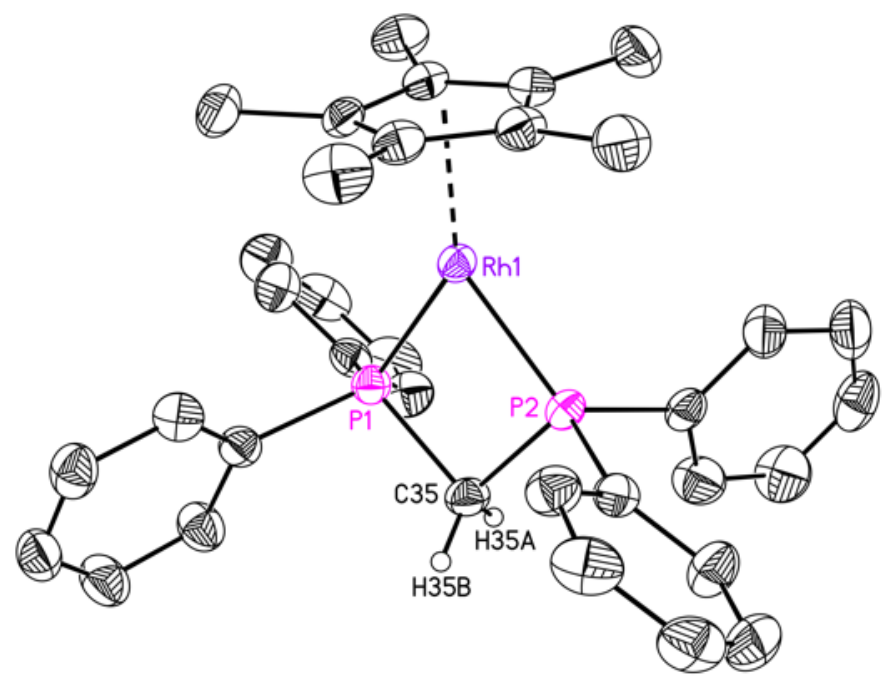

Figure S52: Structure for the asymmetric unit in crystals of 3. Hydrogen atoms, except for H35A and $\mathrm{H} 35 \mathrm{~B}$, are omitted for clarity. Displacement ellipsoids are shown at the $50 \%$ probability level. 


\section{Special Refinement Details for 4}

Complex 4 crystallizes in the monoclinic space group $C 2 / c$. Two co-crystallized toluene molecules are present within the asymmetric unit. One is located in a general position, while the other is disordered across an inversion center. In the final model, both of the aromatic portions of the toluene molecules were fit to ideal hexagons and were allowed to freely rotate. The methyl group was restrained to have reasonable $1,2-$ and $1,3-\mathrm{C} \cdot \bullet \mathrm{C}$ distances and to retain a reasonable geometry. The occupancy of the atoms comprising the toluene molecule in the general position was modified by inspection of the displacement parameters yielding a $25 \%$ occupancy. The toluene that is disordered across the inversion center was modeled at 50\% occupancy. However, mild similarity restraints were applied to the displacement parameters. In the final model, the toluene carbon atoms were modeled with isotropic displacement parameters. 


\section{Solid-State Structure of 4}

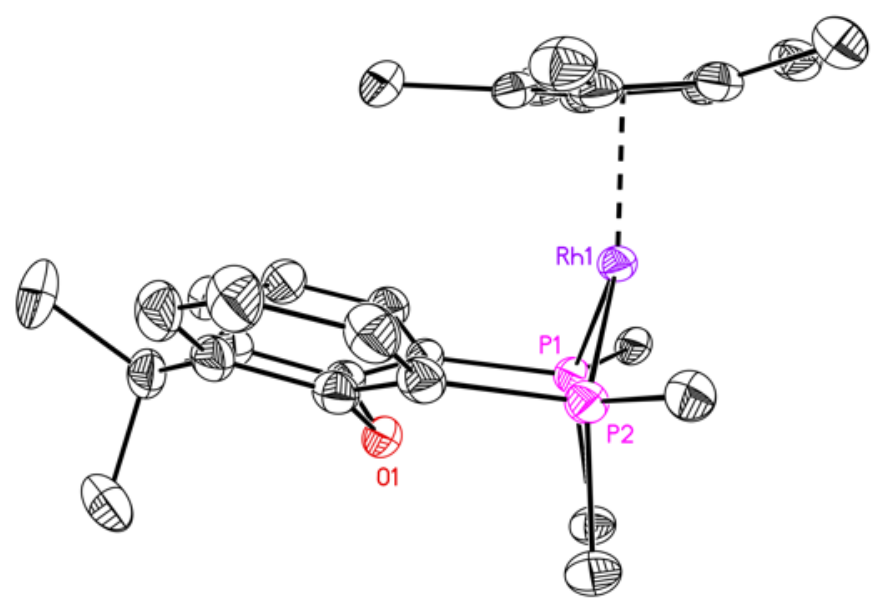

Figure S53: Solid-state structure for the molecular core of the $\mathrm{Rh}(\mathrm{I})$ complex in the asymmetric unit of 4. All hydrogen atoms, additional atoms for the phosphine phenyl rings and the cocrystallized toluene molecules are omitted for clarity. Displacement ellipsoids are shown at the $50 \%$ probability level.

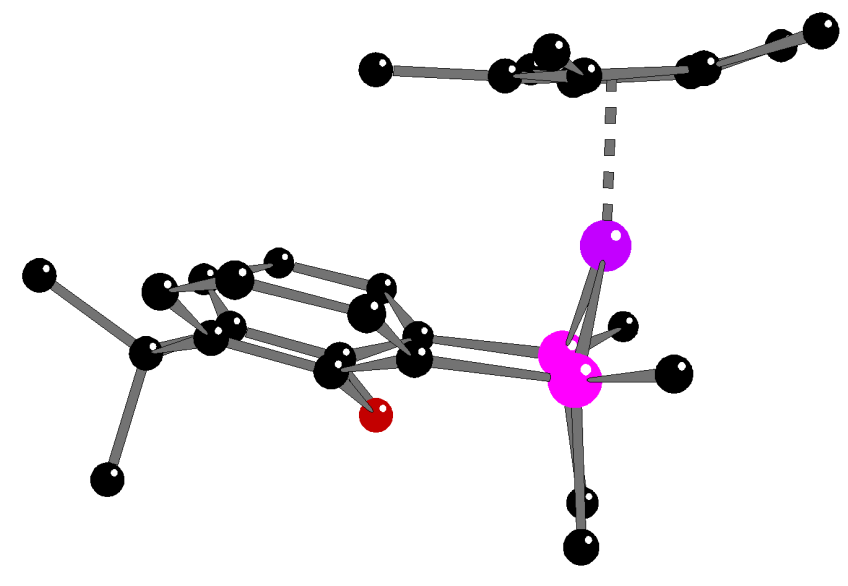

Figure S54: Ball-and-stick representation for the molecular core of the Rh(I) complex in the asymmetric unit for 4 . All hydrogen atoms, additional atoms for the phosphine phenyl rings and the co-crystallized toluene molecules are omitted for clarity. 


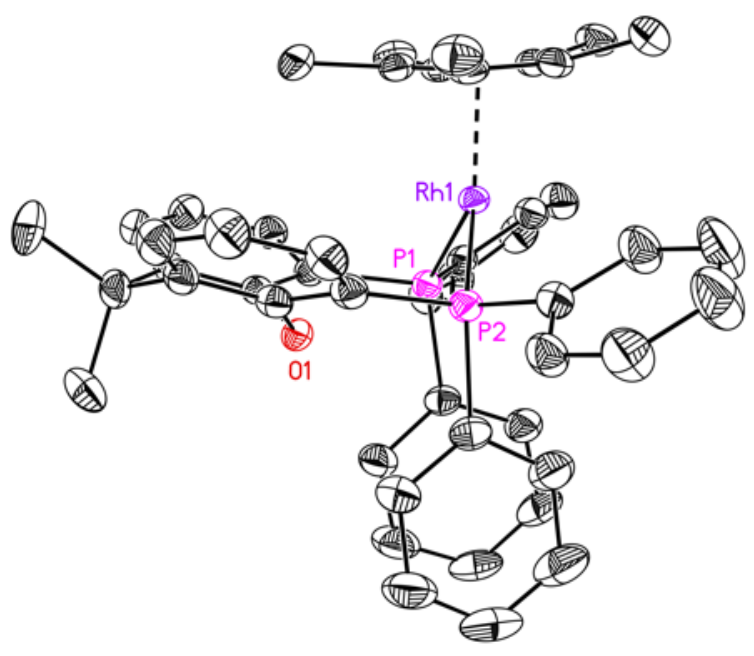

Figure S55: Solid-state structure for the Rh(I) complex in the asymmetric unit of 4. All hydrogen atoms and the co-crystallized toluene molecules are omitted for clarity. Displacement ellipsoids are shown at the $50 \%$ probability level.

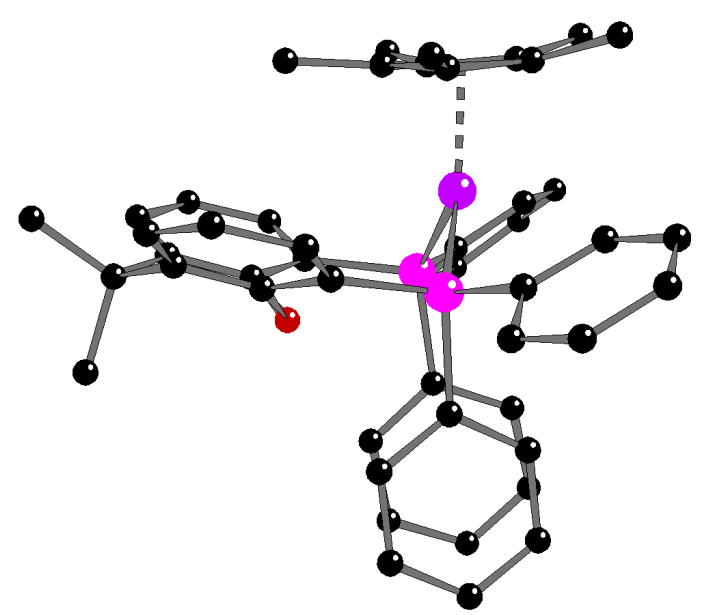

Figure S56: Ball-and-stick representation for the $\mathrm{Rh}(\mathrm{I})$ complex in the asymmetric unit of 4. All hydrogen atoms and the co-crystallized toluene molecules are omitted for clarity. 


\section{Full Asymmetric Unit of 4}
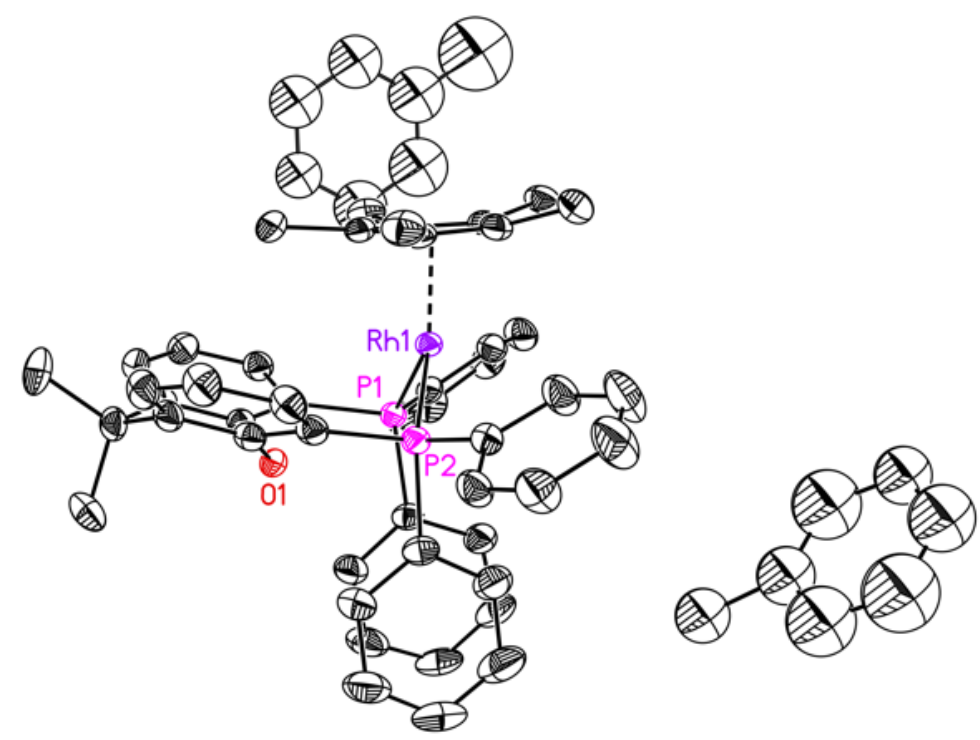

Figure S57: Solid-state structure for the asymmetric unit of 4. Hydrogen atoms are omitted for clarity. Displacement ellipsoids are shown at the 50\% probability level.
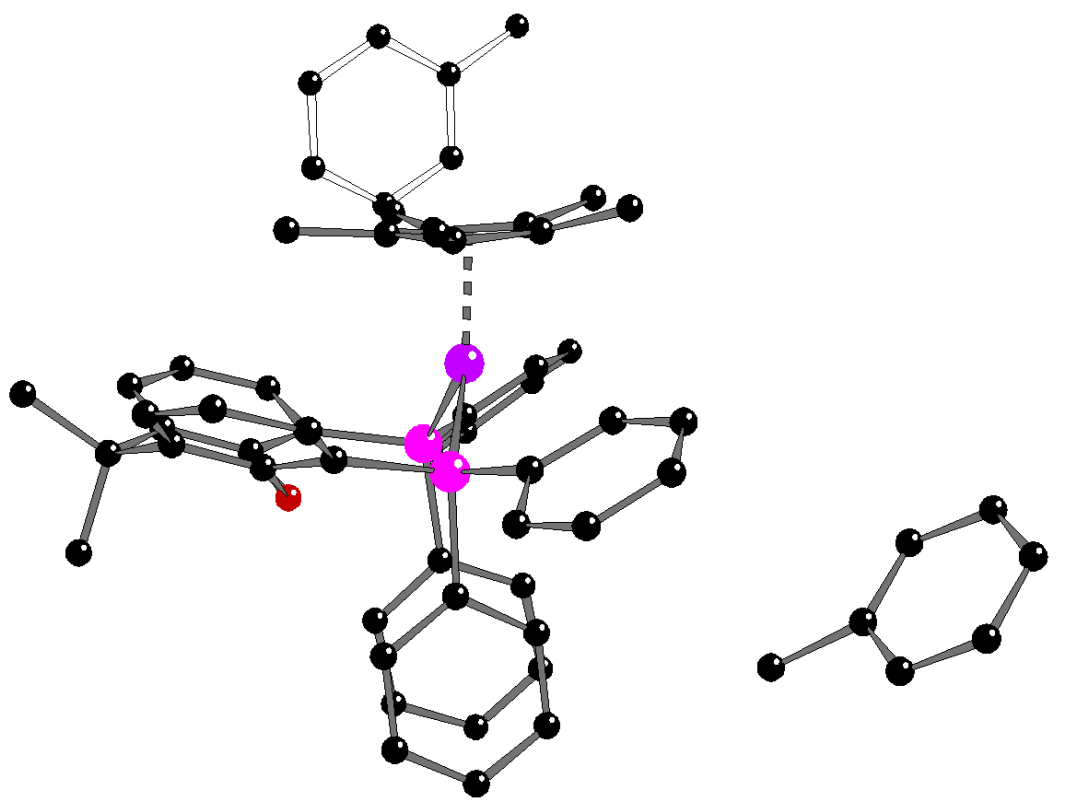

Figure S58: Ball-and-stick representation for the solid-state asymmetric unit of 4. Hydrogen atoms are omitted for clarity. 


\section{Special Refinement Details for 5}

Hydride hydrogen atom H1 was located from a difference Fourier and included in the structural model as an independent isotropic atom whose parameters were allowed to vary in least-squares refinement cycles. 


\section{Solid-State Structure of the Molecular Cation in 5}

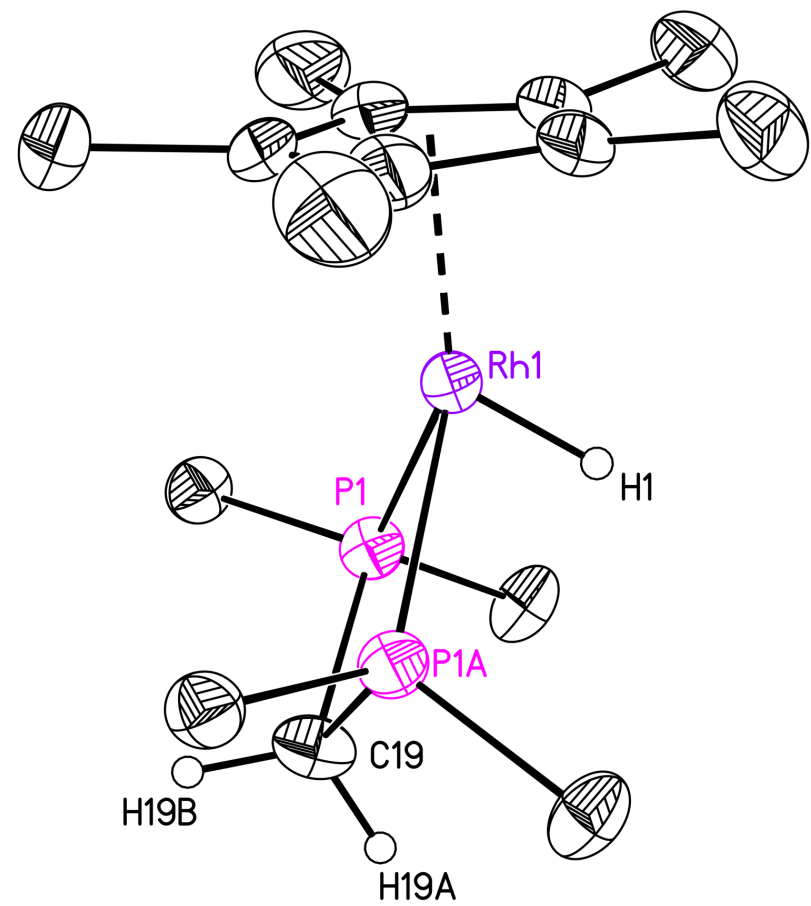

Figure S59: Solid-state structure of the core for the molecular cation in 5. The triflate counteranion is omitted for clarity. The cation possesses rigorous $C_{\mathrm{s}}$ molecular symmetry with Rh1, H1, C19, H19A, H19B and two $\mathrm{Cp}^{*}$ carbon atoms lying in a crystallographic mirror plane at $\mathrm{y}=0.25$. The triflate counteranion, all hydrogen atoms except for H1, H19A and H19B and additional atoms for the phosphine phenyl rings are omitted for clarity. Displacement ellipsoids are shown at the 50\% probability level. 


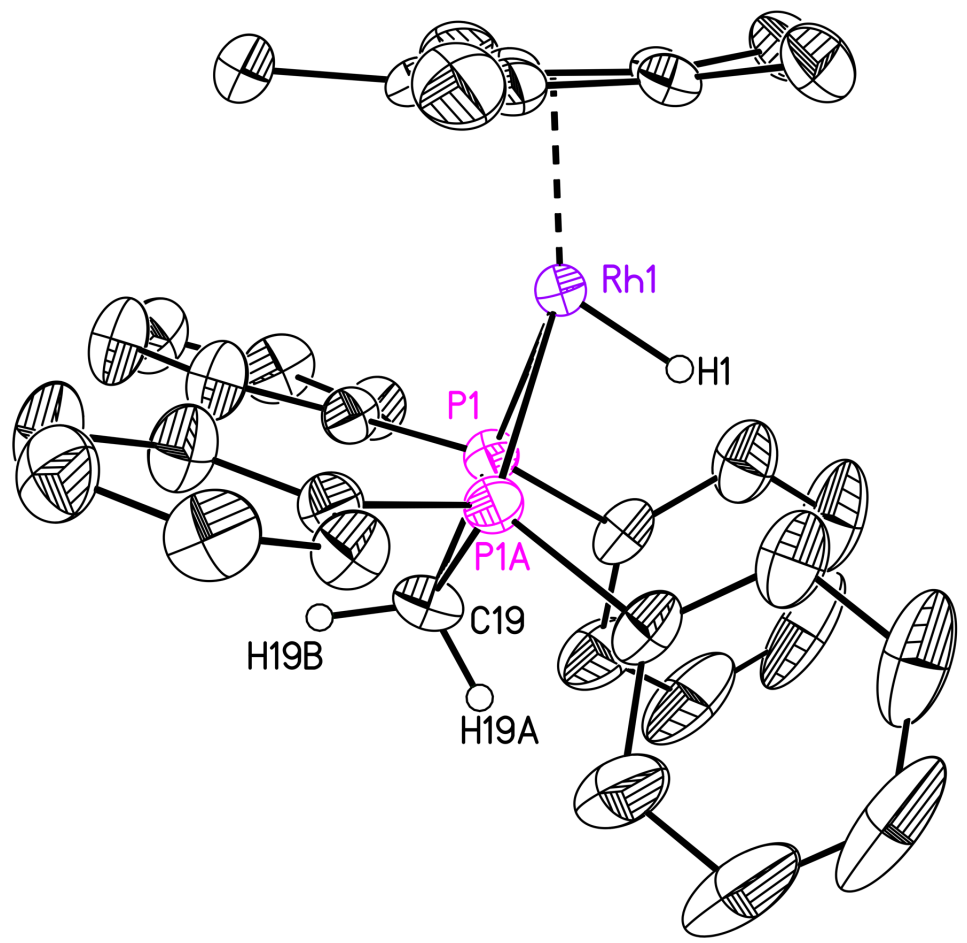

Figure S60: Solid-state structure for the molecular cation in 5. The triflate counteranion and all hydrogen atoms except for H1, H19A and H19B are omitted for clarity. The cation possesses rigorous $C_{\mathrm{s}}$ molecular symmetry with $\mathrm{Rh} 1, \mathrm{H} 1, \mathrm{C} 19, \mathrm{H} 19 \mathrm{~A}, \mathrm{H} 19 \mathrm{~B}$ and two $\mathrm{Cp}^{*}$ carbon atoms lying in a crystallographic mirror plane at $y=0.25$. Displacement ellipsoids are shown at the $50 \%$ probability level. 

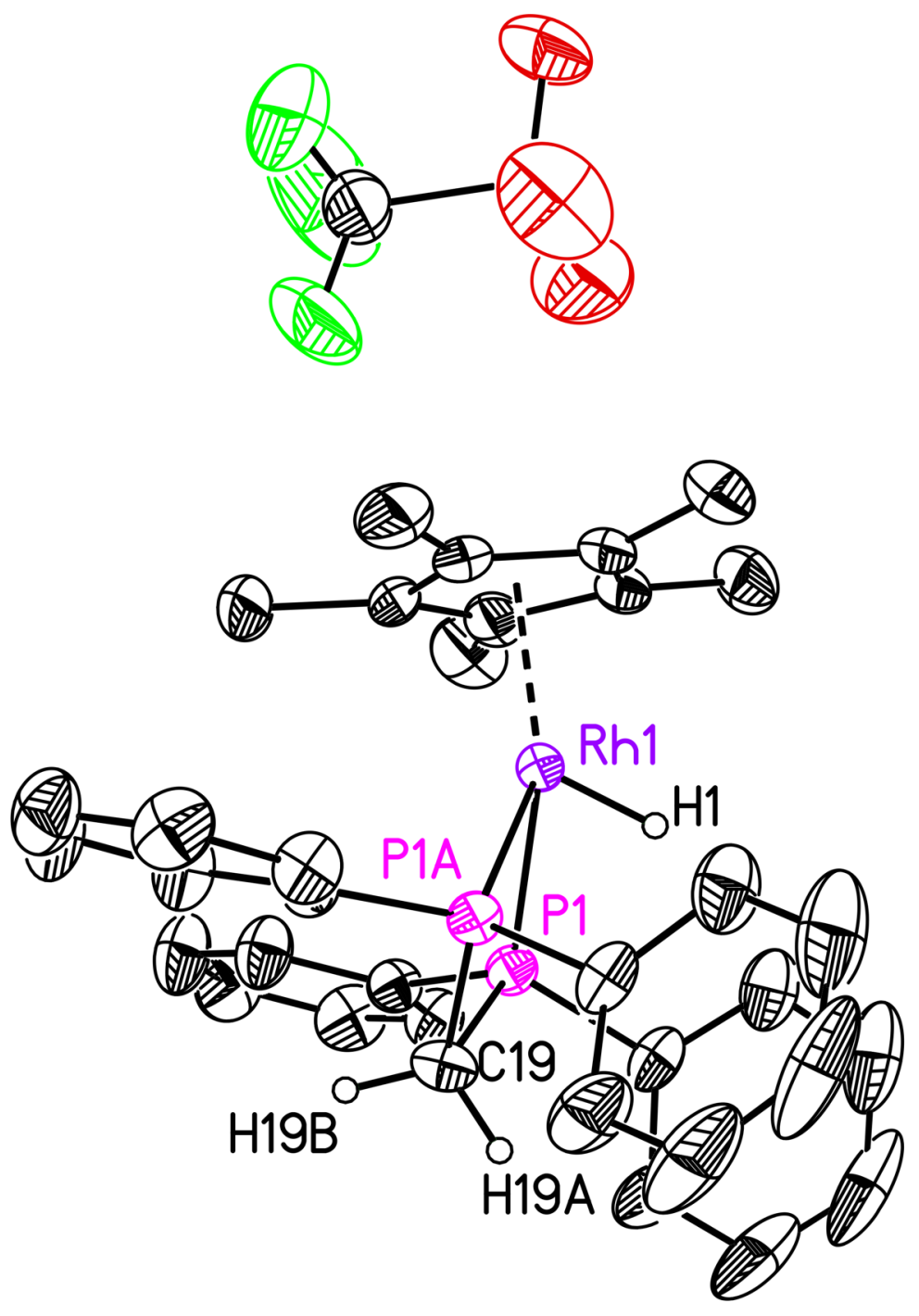

Figure S61: Solid-state structure for two asymmetric units of 5. Hydrogen atoms, except for H1, H19A, and H19B, are omitted for clarity. The cation possesses rigorous $C_{\mathrm{s}}$ molecular symmetry with Rh1, H1, C19, H19A, H19B and two Cp* carbon atoms lying in a crystallographic mirror plane at $y=0.25$. The triflate anion also lies on a crystallographic mirror plane and possesses rigorous $C_{\mathrm{s}}$ molecular symmetry. Displacement ellipsoids are shown at the $50 \%$ probability level. 


\section{Special Refinement Details for 6.}

Hydride hydrogen atoms $\mathrm{H} 1$ and $\mathrm{H} 1$ ' in $\mathbf{6}$ were located from a difference Fourier and included in the structural model as independent isotropic atoms whose parameters were allowed to vary in least-squares refinement cycles. 


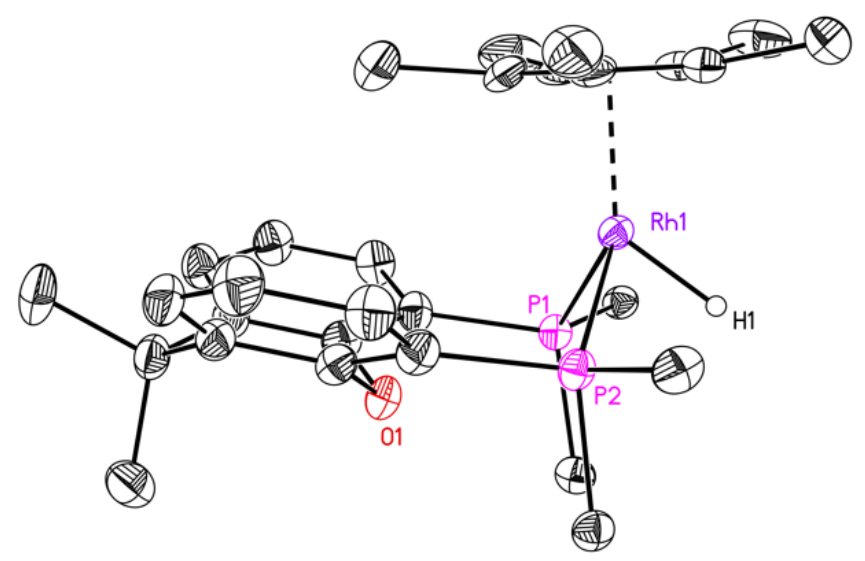

Figure S62: Solid-state structure of the non-hydrogen core for the first of two crystallographicallyindependent and virtually identical molecular cations in the asymmetric unit of $\mathbf{6}$. A second molecular cation of $\mathbf{6}$, two co-crystallized triflate counteranions, all hydrogen atoms except H1 and additional atoms for the phosphine phenyl rings are all omitted for clarity. Displacement ellipsoids are shown at the 50\% probability level.

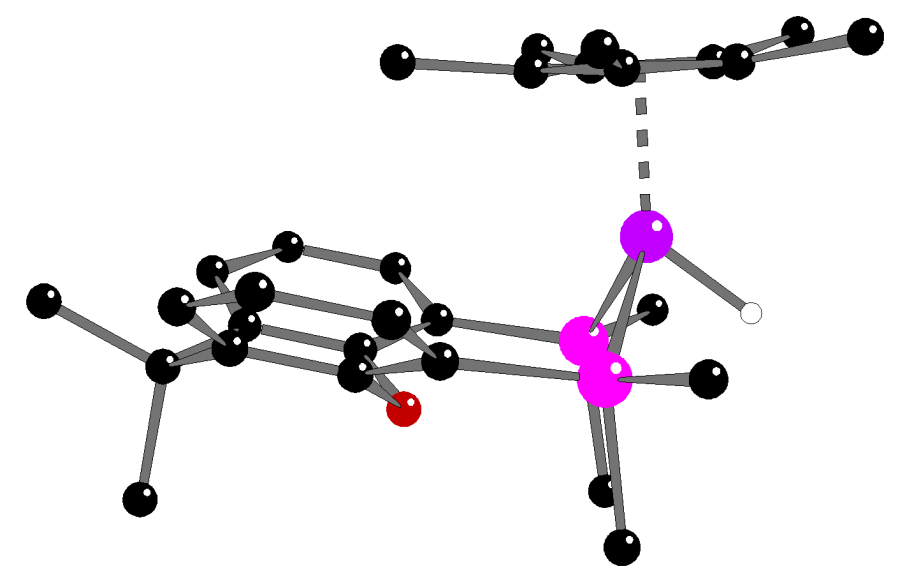

Figure S63: Ball and stick representation of the solid-state structure for the non-hydrogen core for the first of two crystallographically-independent and virtually identical molecular cations in the asymmetric unit of $\mathbf{6}$. A second molecular cation of $\mathbf{6}$, two co-crystallized triflate counteranions, all hydrogen atoms except for the hydride (H1) and additional atoms for the phosphine phenyl rings are all omitted for clarity. 


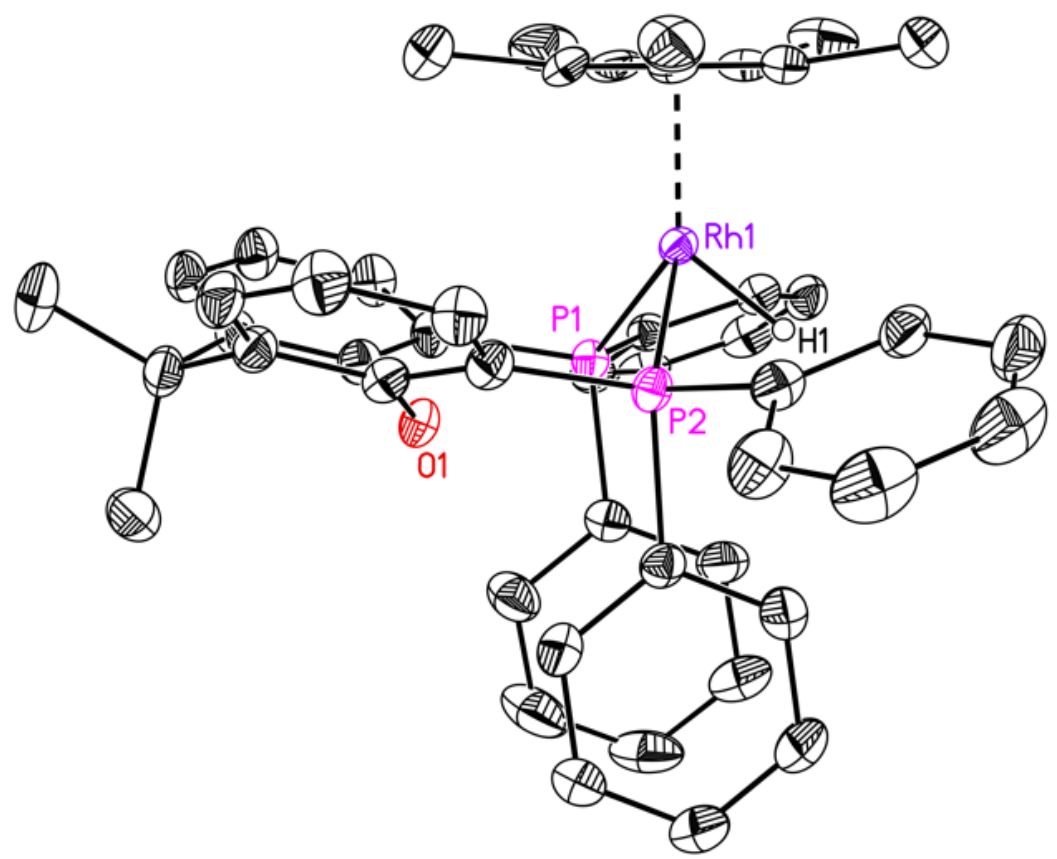

Figure S64: Solid-state structure for the first of two crystallographically-independent and virtually identical molecular cations in the asymmetric unit of 6 . A second molecular cation of 6 , two cocrystallized triflate counteranions and all hydrogen atoms except $\mathrm{H} 1$ are omitted for clarity. Displacement ellipsoids are shown at the 50\% probability level.

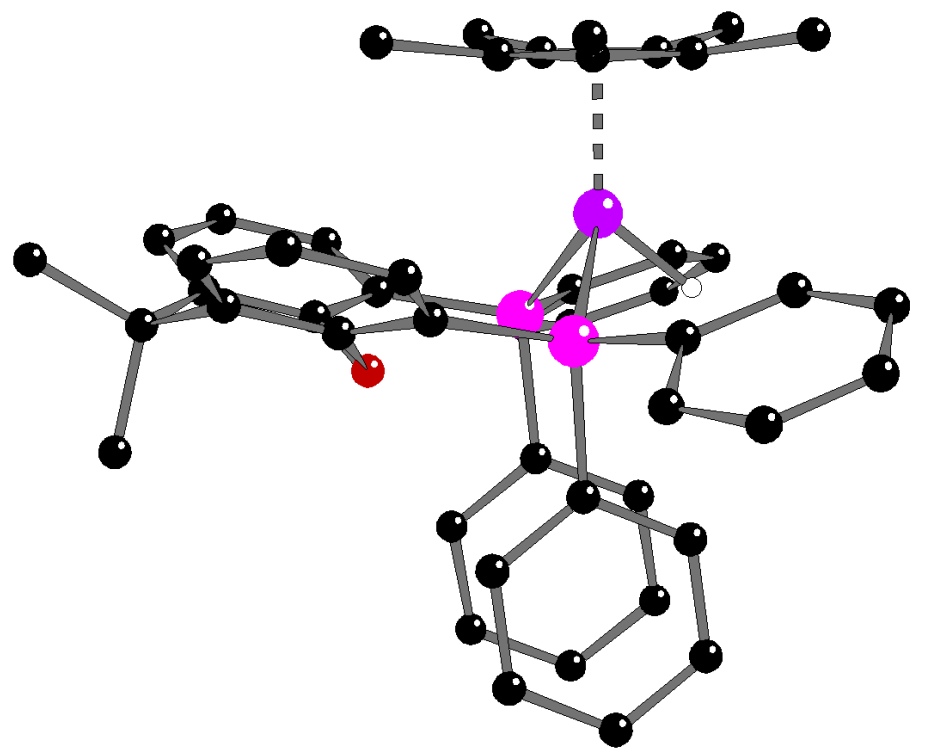

Figure S65: Ball-and-stick representation for the first of two crystallographically-independent and virtually identical molecular cations in the asymmetric unit of $\mathbf{6}$. A second molecular cation of $\mathbf{6}$, two co-crystallized triflate counteranions and all hydrogen atoms except the hydride are all omitted for clarity. 


\section{Asymmetric Unit of 6}

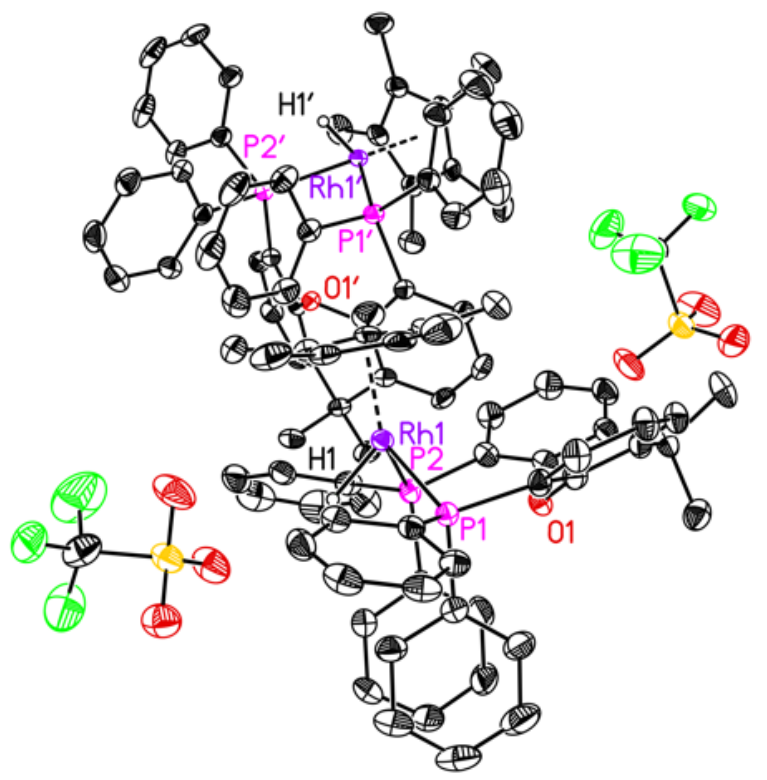

Figure S66: Solid-state structure of the asymmetric unit for 6. Hydrogen atoms except the hydrides are all omitted for clarity. Displacement ellipsoids are shown at the 50\% probability level. Atoms of the second crystallographically-independent cation are labeled with a prime $(')$.

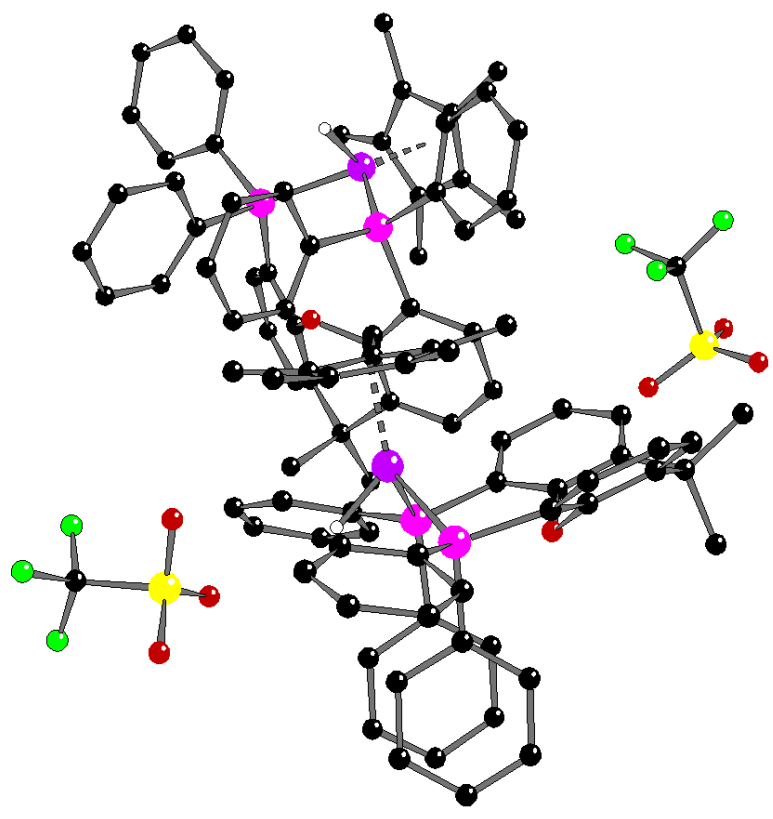

Figure S67: Ball and stick representation of the solid-state asymmetric unit for $\mathbf{6}$. Hydrogen atoms except the hydrides are all omitted for clarity. 


\section{References}

${ }^{1}$ APEX2, Version 2 User Manual, M86-E01078,; Bruker Analytical X-ray Systems: Madison, WI, June 2006.

${ }^{2}$ G. M.Sheldrick, SADABS (version 2008/1): Program for Absorption Correction for Data from Area Detector Frames, University of Göttingen, 2008.

${ }^{3}$ G. Sheldrick, Crystal structure refinement with SHELXL. Acta Crystallogr., Sect. A: Found. Crystallogr. 2015, 71, 3-8.

${ }^{4}$ O. V. Dolomanov, L. J. Bourhis, R. J. Gildea, J. A. K. Howard, H. J. Puschmann, Appl. Crystallogr. 2009, 42, 339-341. 